\title{
Identification of QTLs for behavioral reactivity to social separation and humans in sheep using the OvineSNP50 BeadChip
}

Dominique Hazard ${ }^{1,2,3^{*}}$, Carole Moreno ${ }^{1,2,3}$, Didier Foulquié ${ }^{4}$, Eric Delval ${ }^{5,6,7}$, Dominique François ${ }^{1,2,3}$, Jacques Bouix ${ }^{1,2,3}$, Guillaume Sallé, ${ }^{1,2,3}$ and Alain Boissy $y^{5,6,7}$

\begin{abstract}
Background: Current trends in sheep farming practices rely on animals with a greater level of behavioral autonomy than before, a phenotype that actively contributes to the sustainability of animal production. Social reactivity and reactivity to humans are relevant behavioral traits in sheep, known for their strong gregariousness and weak tolerance to handling, which have previously been reported with moderate to high heritabilities. To identify loci underlying such behaviors, we performed a genome study in Romane lambs.

Results: The experiment was carried out on 934 male and female lambs allocated into 9 half-sib families (average of 103 lambs per family) and reared outside. After weaning, all the lambs were individually exposed to 4 standardized behavioral tests combining social isolation, exposure to humans or handling, confinement and novelty (i.e. arena test, corridor test, isolation box test, shearing test). A broad range of behaviors including vocalizations, locomotion, vigilance and flight distance, as well as the cortisol response to handling, were collected. All lambs were genotyped using the Illumina OvineSNP50 BeadChip. QTL detection was performed by linkage, association and joint linkage and association analyses using the QTLmap software. Five main QTL regions were identified on sheep chromosomes (Ovis Aries Region, OAR) 12, 16, 19, 21 and 23 among many other QTLs with small to moderate effects. The QTLs on OAR12, 16 and 21 showed significant associations with social reactivity. The QTLs on OAR19 and 23 were found to be associated with reactivity to humans. No overlapping QTLs were identified for the different traits measured in the behavioral tests, supporting the hypothesis that different genetic factors influence social reactivity and tolerance to humans.
\end{abstract}

Conclusion: The results of this study using ovine SNP data suggest that in domestic sheep the behavioral responses to social separation and exposure to humans are under polygenic influence. The most relevant QTLS reported in the present study contain interesting candidate genes previously described to be associated with various emotional and social behaviors in mammals.

Keywords: Sheep, Behavioral reactivity, Quantitative trait loci, Gregariousness, Human, Cortisol

\footnotetext{
* Correspondence: dominique.hazard@toulouse.inra.fr

'INRA, UMR1388 Génétique, Physiologie et Systèmes d'Elevage, F-31326

Castanet-Tolosan, France

${ }^{2}$ Université de Toulouse INPT ENSAT, UMR1388 Génétique, Physiologie et

Systèmes d'Elevage, F-31326 Castanet-Tolosan, France

Full list of author information is available at the end of the article
} 


\section{Background}

Behavioral adaptation of farm animals to various rearing conditions is a growing concern. Whatever the rearing system, farms animals are often faced with physical and social environmental changes that they have to cope with by developing adapted behavioral and/or physiological responses [1-3]. Animals respond, both behaviorally and physiologically, to challenges in order to maintain homeostasis $[4,5]$ that contributes highly to their fitness. The development of modern production systems and selection for production traits has induced a rise in the prevalence of behavioral disorders [6,7]. The difficulties experienced by some animals when faced with social challenges, such as isolation or social instability in sheep [8], may cause poor welfare and production loss [9-14]. On the other hand, the reduced manning levels on livestock farms combined with the increased size of herds leads to a lesser exposure to humans [15]. As a consequence, animals are more likely to experience stress during routine husbandry procedures [16]. Human-animal interaction studies previously reported the negative effects of high behavioral reactivity to humans on production traits $[15,16]$. The social skills of the farm animal, including social tolerance, social facilitation or maternal behavior, are actively involved in helping it adapt to its environment [17].

Genetic selection for behavioral traits could be an advantageous strategy aimed at improving the ability of animals to adapt to modern rearing conditions by reducing, for instance, the susceptibility of an animal to changes in its physical environment, limiting excessive fear of humans and improving sociability [18]. In the past, most studies on the genetics of behavior in mammals have focused on rodents, where the existence of inbred lines, for instance in mice, has increased the power to detect quantitative trait loci (QTL) [19] and to identify candidates genes related to behavior [20-22]. Although findings in rodents may give new insights into the understanding of various behaviors in mammals, some gene effects (i.e. allelic variants) may be species-specific, and therefore QTLs identified in rodents may not be relevant in livestock species, and vice versa. Moreover, the exploration of some behaviors, such as reactivity to humans, is only relevant in livestock species.

Animal behavior is a complex concept that has been shown to be influenced by a large variety of factors. A number of studies have focused on the development of standard tests to evaluate the variability of the behavioral response of sheep to novelty, social isolation, attraction for conspecifics or the presence of a human [23-26]. For instance, the arena test has been used in sheep to evaluate temperament [27], to assess sociability [28] and to investigate a possible selection criterion for lamb-rearing ability $[14,29]$. The arena test has been combined with an isolation box test to divergently select for temperament in sheep [30,31].
In livestock species, and more particularly in sheep, genetic variation between breeds has been reported to explain differences of behavioral reactivity in standard tests [25,32-34]. Medium to high heritabilities (0.20 to 0.49) have been reported within various breeds of sheep for several behavioral traits involved in social reactivity $[25,35]$. As regards to the reactivity to humans in particular, heritability estimates were moderate both in sheep (0.17 to $0.32)$ [25] and cattle (0.17 to 0.24$)$ [12,13,36]. However, QTL studies for behavior are still scarce in livestock species (for review see [37]). For instance, QTLs for social behavior have been found in fish [38] and chickens [39], and QTLs for reactivity to humans have been reported in dairy and beef cattle [40,41].

In sheep, while major genes or QTLs have been reported for reproduction [42], production [43] and health traits [44] (for a review see [45]), no such studies have been undertaken for behavioral traits. The recent development of genome-wide analyses in sheep provides new opportunities for better understanding of the genetic components of various behaviors, with potential applications in the improvement of such traits. Taking advantage of such developments and considering the existing genetic variability for some behavioral traits found in domestic sheep, the aim of the present study was to perform QTL detection for behavioral and physiological traits in purebred sheep. We focused our study in particular on the reactivity of sheep measured in response to social isolation and/or human presence/handling.

\section{Methods}

\section{Animals and management}

The experimental animals were Romane lambs (historically named INRA401), a fixed crossbreed between Romanov $\mathrm{x}$ Berrichon du Cher [46]. A total of 1099 male and female lambs born over 5 years (approximately 220 lambs per year) and allocated in 9 half-sib families (on average 122 lambs per family) were used in this study. The animals were reared and experiments were conducted at the INRA experimental farm of La Fage (Roquefort sur Soulzon, France). All the animals were born in the spring and reared exclusively outdoors with their dams under extensive conditions (approximately 1 ewe/ha). The farming system and management characteristics have previously been described by Gonzalez et al. [47]. All lambs were identified at birth using ear tags and weaned at $75 \pm$ 4 days of age. After weaning, lambs were maintained as a single flock and had minimal contact with humans until the period of the behavioral tests.

\section{Ethics statement}

The experiments described here and performed before 2013 fully comply with the legislation on research involving animal subjects according to the European Union 
Council Directive of November 24, 1986 (86/609/EEC). The investigators carrying out the experiments were certified by the relevant French governmental authority. All experimental procedures were approved by the Animal Care Committee of Aveyron Veterinary Center under guidelines for the care and use of experimental animals established by the French Ministry of Agriculture ethics policy (agreement $\left.\mathrm{n}^{\circ} 12-004\right)$.

\section{General experimental design}

Experimental lambs were individually exposed to a series of 4 reactivity tests combining social attraction or isolation, exposure to humans/handling, confinement and novelty: 1) an arena test, 2) a corridor test, 3) an isolation box test, and 4) a shearing test. The arena and corridor tests were adapted from the tests developed by Boissy and colleagues [25]. The isolation box test was developed by Murphy [48] and has been used for experimental selection for temperament in Merino sheep [30]. The shearing procedure was standardized to assess cortisol concentrations in response to an aversive handling event.

The arena and corridor tests were performed indoors between 10 and 20 days after weaning (about 30 animals per day for both tests). The day before being tested, the lambs to be tested were removed from the flock and penned under a shelter where they had permanent access to hay, concentrate and water (except during the actual testing time). At the end of the testing day, the lambs were returned to their flock. The isolation box test was carried out 3 weeks after weaning for all the animals of the year's flock. One week later, the shearing test was carried out on the female lambs only (i.e. male lambs were fattened and sold without being shorn).

\section{Arena test}

The aim of the arena test (AT) was to evaluate the social motivation of the lambs and their reactivity to a motionless human. The test consisted of two successive phases evaluating 1) reactivity to social isolation and 2) reactivity to a conflict between social attraction and avoidance of a motionless human. The test pen consisted in an unfamiliar enclosure virtually divided into 7 zones (zone 7 being the zone nearest to conspecifics) as described in detail by Ligout et al. [28]. In our experiment, the first phase of the test (arena test phase 1, AT1) began once the tested animal joined its flock-mates located behind a grid at the opposite side of the arena (time duration for joining: lower than $15 \mathrm{sec}$ ). At this time, an opaque panel was pulled down (from the outside of the pen) between the flock-mates and the tested lamb to prevent visual contact. After one minute the phase 1 stopped and the panel was pulled up so the lamb could see its flock-mates again. Once the lamb had returned near to its flock-mates, or after 1 minute if the lamb did not do so, a non-familiar human slowly entered the arena through a door located near the pen of the flock-mates, and stood $20 \mathrm{~cm}$ in front of the grid separating the arena from the lamb's flock-mates. The second phase (arena test phase 2, AT2) began once the human was in place and lasted for a further 1 minute.

\section{Corridor test}

The corridor test (CT) evaluated reactivity to social isolation and to an approaching human. It consisted of two successive phases: 1) reactivity to social isolation, and 2) reactivity to a walking human (i.e. repeated approaches). The test pen consisted in a closed, wide rectangular circuit and has been described in detail by Boissy et al. [25]. The first phase (corridor test phase 1, CT1) began when the lamb entered the testing pen and lasted for 30 seconds. After that time a non-familiar human entered the testing pen and the second phase (corridor test phase 2, CT2) started and lasted 1 minute. During this phase, the human walked at a regular speed through the corridor (the corridor was divided into 6 virtual zones and one zone was crossed every 5 seconds) until two complete tours had been achieved. Every five seconds throughout this phase, the zones in which the human and the animal were located were recorded, and the walking human recorded with a stopwatch the total duration during which the head of the lamb was visible.

\section{Isolation box test}

The aim of the isolation box test (IBT) was to evaluate the reactivity of the lambs to social isolation, novelty and confinement [30]. A $1.5 \times 1.5 \times 1.5 \mathrm{~m}$ wooden box resting on four tires was placed in the animals' pasture. Lambs were then moved as a group into a waiting pen near the box and then each lamb was individually introduced into the isolation box and maintained within the box for 30 seconds. The agitation of the isolated lamb was recorded using an electronic 'agitatometer' (Physiology Electronics, University of Western Australia) registering each vibration of the box resulting from the movements of the lamb. In order to minimize any potential variation along the time, a calibration of the agitometer was performed before each testing day: the sensitivity of the agitometer was readjusted by using a calibration unit (University of Western Australia) that was placed on the floor of the IBT and produced repetitive and standardized vibrations simulating the action of a lamb whilst in the box.

\section{Shearing test}

The shearing test assessed the rise in cortisol levels due to the stress induced by the shearing procedure. The test was carried out only on females. The ewe-lamb flock was gathered in a waiting area. One investigator caught 
the lamb to be shorn 15 seconds before the shearer finished shearing the previous animal and maintained it motionless 2 meters away from the shearer until it was its turn. The shearer then caught the animal and the shearing procedure began and lasted no longer than 1.5 minutes. The lamb was then released in a corridor made of metal hurdles in contact with its flock mates. Fifteen minutes after being sheared, another investigator caught the animal and maintained it motionless with its head up while a third investigator took a blood sample from jugular vein. The lamb was then released to pasture. The blood sample was centrifuged within a few minutes and plasma samples were transferred and frozen to be later assayed for cortisol concentration (CORT) by radioimmunoassay [49].

\section{Behavioral traits}

Arena and corridor tests were video recorded. Locomotor activity, vigilance postures, and behaviors to the flockmates or the human, were measured afterwards using the video software The Observer 6.0 (Noldus). Locomotor activity was assessed by measuring the number of zones crossed during arena test phases 1 and 2 (AT1/2LOCOM) and corridor test phase 1 (CT1-LOCOM). The overall degree of agitation during the isolation box test was measured objectively using an electronic 'agitation meter' (IBT-LOCOM). Vigilance postures (i.e. animal motionless, head in an upright position and ears perpendicular to the head) were measured during arena test phase 1 (AT1-VIGIL). The proximity to flock-mates and the human during arena test phase 2 was calculated using the following formula: AT2-PROX $=($ time spent in zone $1 \times 0 / 6)+($ time spent in zone $2 \times 1 / 6)+\ldots+$ (time spent in zone $7 \times 6 / 6$ ). Deviation from normal distribution is minimized using this formula compared with the formula described by Ligout et al. [28]. The mean distance separating the human and the lamb and the time during which the human saw the lamb were measured for corridor test phase 2 (CT2-DIST and CT2-SEEN, respectively). During the actual tests, an investigator counted the lamb's vocalizations from outside the pen using a laptop: number of times the animal bleated with an open mouth (high bleats, AT1/2HBLEAT, CT1-HBLEAT, IBT-HBLEAT), and number of times the animal bleated with a closed mouth (low bleats, AT1/2-LBLEAT, CT1-LBLEAT). Only high bleats were recorded during arena test phase 2 and the isolation box test.

\section{Statistical handling}

Deviations from normality of row data were tested using the Kolmogorov-Smirnov test (Univariate procedure of SAS, SAS Institute Inc.). Several raw measures were transformed in order to minimize major deviations from the normal distribution. Square root transformation was applied to AT1/2-HBLEAT, CT1-HBLEAT, IBT-HBLEAT and IBT-LOCOM. Logarithmic transformation was applied to AT1/2-LBLEAT, CT1-LBLEAT and CORT. A multivariate analysis was performed to take into account the multidimensional aspect of behavioral responses. Principal component analysis (PCA), followed by orthogonal rotation was carried out using $\mathrm{SAS}^{\oplus}$ software (FACTOR procedure, version 8.1, $\mathrm{SAS}^{\oplus}$ Institute Inc., Cary, NC, USA). Factor scores were then calculated for each lamb and used in subsequent analyses. In addition, we constructed four synthetic variables using PCA (PRINCOMP procedure in the $\mathrm{SAS}^{\odot}$ software). Each PCA was performed for a set of similar behavioral variables across the three behavioral tests. The first component of each PCA, explaining the largest part of total variance, was defined as a synthetic variable. Three synthetic variables were specific to the reactivity to social isolation: high bleats (ISO_HBLEAT), locomotion (ISO_LOCOM) and low bleats (ISO_LBLEAT). One synthetic variable was specific to the reactivity to a human: the tolerance to being approached when the lamb was free to flee (HUMAPPRO). The correlations between original measurements and the 4 synthetic variables ranged between 0.64 and 0.93 . The synthetic variables accounted for $46 \%$ to $87 \%$ of the total variability. Analyses of variance using the GLM procedure of the $\mathrm{SAS}^{\oplus}$ software were performed on the original and synthetic variables to assess differences between the lambs for different rearing year, sex, litter size born and litter size reared, and the age of the mother. Phenotypes were then corrected for identified fixed effects prior to subsequent genetic analyses (Additional file 1). Heritability estimates were generated for each trait by restricted maximum likelihood (REML) methodology using univariate analyses with VCE 4.2.5 software (Neumaier and Groeneveld, 1998). Random effects in the mixed models included a direct genetic effect (animal), a maternal permanent environment effect and a litter permanent environment effect.

\section{SNP genotypes}

1038 lambs (out of the 1099 lambs phenotyped) were genotyped as well as their nine respective sires using the Illumina OvineSNP50 BeadChip (comprising 54,241 SNPs). Individuals with a call rate (i.e. number of called SNPs per sample over the total number of SNPs in the data set) below 98\% and with Mendelian inconsistencies (i.e. no alleles shared between it's a sire and its progeny for a given SNP) were discarded (104 and 9 lambs, respectively). SNP quality was also checked as described by Sallé et al. [44]. 5448 SNPs with a call rate lower than $97 \%$, a minor allele frequency below $1 \%$ or inconsistent Hardy-Weinberg disequilibrium were discarded. 
Furthermore, 3095 SNPs were discarded due to a too high recombination rate or because more than $50 \%$ of heterozygous sire's offspring were heterozygous. Sex chromosomes were not included in the analysis. Finally, 934 individuals and 40,725 autosomous SNPs were retained for QTL analyses.

\section{Methods for QTL detection}

The QTLmap software was used to search for QTLs using linkage, association and joint linkage and association analyses [50].

\section{Linkage analysis}

Data were analyzed using linkage analyses (LA) by interval mapping within each sire family. The presence of a QTL was tested against the null hypothesis (absence of a QTL) at every 0.1-cM interval by likelihood computation. Chromosome-wise significance levels were computed for each chromosome and trait by testing with 3000 to 10,000 permutations [51]. Genome-wise thresholds were obtained using the Bonferroni correction $\left(1-\mathrm{P}_{\text {genome wise }}\right)=\left(1-\mathrm{P}_{\text {chromosome wise }}\right)^{\mathrm{n}}$ where $\mathrm{n}$ is the number of chromosomes (i.e. 26 autosomous chromosomes in sheep) [52]. Confidence intervals were determined using the "2 lod drop off" criterion and assuming $1 \mathrm{LOD}=4.61$ LRT [53].

\section{Association analysis and joint linkage and association analysis}

Genome-wide association (GWAS) analysis was performed for the whole population genotyped using the existing linkage disequilibrium (LD) [54]. The LD linear model (named LD decay model) developed by Legarra et al. [55] was fitted to our data. The advantage of this LD method is that it be used with estimated haplotype effects.

Joint analysis (LDLA), considering simultaneously linkage association and linkage disequilibrium, was performed to take advantage of both pedigree and LD [55]. The LDLA model considered the sire haplotype effects of the LD model in addition to sire QTL effects.

Finer mapping was achieved with both GWAS and LDLA approaches than with linkage analysis alone. Assuming approximately 10 SNPs per cM in our study, the limit of accuracy may therefore be the LD pattern in our data. For both GWAS and LDLA analyses, a haplotype size of 4 SNPs was used. When haplotype frequency was lower than $1 \%$, haplotypes were considered to belong to a rare haplotype group. The chromosome-wise p-values were estimated assuming that, conditional on the QTL position, the likelihood ratio test statistics followed a $X^{2-}$ distribution with $\mathrm{k}$ degrees of freedom, $\mathrm{k}$ being the number of genetic effects [56]. In our study, $\mathrm{k}$ was equal to the number of haplotypes for GWAS and the number of haplotypes plus the number of families for LDLA. Genome-wise p-values were obtained using the Bonferroni correction assuming 26 chromosomes were analyzed (i.e. 26 independent tests) [52,57].

\section{Results \\ Phenotypes}

Descriptive statistics of behavioral traits are summarized in Table 1. Locomotion in arena test phase 1 and agitation in the isolation box test were approximately 3 to 4 fold higher than in arena test phase 2 and corridor test phase 1 . The highest and lowest numbers of high bleats were recorded in arena test phase 1 and 2, respectively, while the number of high bleats recorded in corridor test phase 1 and the isolation box test were intermediate. The number of low bleats was low whatever the test (in average less than 2.6 low bleats). Lambs spent in average one third of test duration in vigilance postures during arena test phase 1 . Proximity to flock-mates and the human in arena test phase 2 was in average $27 \mathrm{~s}$, which is approximately 2.2 fold lower than the maximum proximity duration (60 s). The mean distance separating the human and the lamb in corridor test phase 2 was $5.4 \mathrm{~m}$ and the mean time during which the human could see the lamb was $11 \mathrm{~s}$. The mean cortisol concentration in response to the shearing procedure was $46.7 \mathrm{ng} / \mathrm{ml}$. Factor analysis of the data revealed that four main factors accounted for $57.1 \%$ of the variability. Orthogonal rotation resulted in the factor loadings shown in (Additional file 2: Table S4). Factor 1 had high positive loadings for the frequency of the lamb to perform high bleats whatever the test and was designated "High Bleats". Factor 2 had high positive loadings for proximity to a human and time during which the human could see the lamb and a negative loading for the mean distance separating the human and the lamb. Factor 2 was designated "Reactivity to humans". Factor 3 had high positive loadings for the number of zones crossed whatever the test and a negative loading for vigilance postures. Factor 3 was designated "Locomotor activity". Factor 4 had high positive loadings for the frequency of the lamb to perform low bleats whatever the test and was designated "Low Bleats".

\section{Linkage analysis}

Eleven significant QTLs reaching the 1\% chromosomewise $(\mathrm{CW})$ threshold and 10 significant QTLs reaching genome-wise $(\mathrm{GW})$ thresholds (i.e. $5 \%, 1 \%$ or $0.1 \%$ ) were mapped on OAR 5, 6, 10, 12, 13, 16, 17, 20, 21 and 24 (Table 2). Seventeen of these 21 QTLs were related to vocalizations (AT2/CT1/IBT/ISO-HBLEAT, FACTOR1, AT1/CT1/ISO-LBLEAT, FACTOR4), two QTLs were related to locomotor activity (AT2-LOCOM), one was related to the mean distance separating the human and the lamb (CT2-DIST) and one to the reactivity to 
Table 1 Summary statistics for the original and transformed measures recorded in lambs individually exposed to the behavioral tests

\begin{tabular}{|c|c|c|c|c|c|c|c|c|c|}
\hline \multirow[b]{2}{*}{ Variable } & \multirow[b]{2}{*}{$\mathbf{n}$} & \multirow[b]{2}{*}{ Description } & \multicolumn{3}{|c|}{ Original data } & \multicolumn{4}{|c|}{ Transformed data } \\
\hline & & & Mean ( \pm SD) & Min & Max & Mean ( \pm SD) & Min & Max & Transformation \\
\hline AT1-LOCOM & 1066 & number & $19.83(8.80)$ & 1 & 50 & & & & none \\
\hline AT2-LOCOM & 1066 & number & $4.84(4.15)$ & 1 & 36 & & & & none \\
\hline AT1-HBLEAT & 1099 & number & $10.59(7.06)$ & 0 & 40 & $2.95(1.38)$ & 0 & 6.33 & Square root \\
\hline AT2-HBLEAT & 1099 & number & $2.50(3.53)$ & 0 & 26 & $1.09(1.15)$ & 0 & 5.10 & Square root \\
\hline AT1-LBLEAT & 1099 & number & $2.65(3.21)$ & 0 & 21 & $0.41(0.36)$ & 0 & 1.34 & $\log$ \\
\hline AT2-LBLEAT & 1099 & number & $1.09(2.02)$ & 0 & 12 & $0.20(0.29)$ & 0 & 1.11 & $\log$ \\
\hline AT1-VIGIL & 1066 & duration (s) & $20.34(9.82)$ & 0 & 51.76 & & & & none \\
\hline AT2-PROX & 1033 & duration (s) & $26.7(16.94)$ & 0 & 60 & & & & none \\
\hline CT1-LOCOM & 1099 & number & $5.92(2.21)$ & 1 & 14 & & & & none \\
\hline CT1-HBLEAT & 1099 & number & $3.20(3.39)$ & 0 & 22 & $1.38(1.14)$ & 0 & 4.69 & Square root \\
\hline CT1-LBLEAT & 1099 & number & $1.70(1.99)$ & 0 & 10 & $0.33(0.30)$ & 0 & 1.04 & $\log$ \\
\hline CT2-DIST & 1099 & distance $(m)$ & $5.39(1.16)$ & 1.75 & 9 & & & & none \\
\hline CT2-SEEN & 1099 & duration (s) & $10.55(7.18)$ & 0 & 59 & & & & none \\
\hline IBT-LOCOM & 1094 & number & $17.81(15.50)$ & 0 & 149 & $3.86(1.70)$ & 0 & 12.21 & Square root \\
\hline IBT-HBLEAT & 1094 & number & $5.62(5.03)$ & 0 & 35 & $2.01(1.26)$ & 0 & 5.92 & Square root \\
\hline$\overline{\text { CORT }}$ & 477 & concentration (ng/ml) & $46.74(18.48)$ & 16 & 127.90 & $1.64(0.17)$ & 1.20 & 2.11 & Log \\
\hline
\end{tabular}

humans (FACTOR2). In addition, 28 significant QTLs reaching the $5 \% \mathrm{CW}$ threshold were detected and mapped on 14 chromosomes (Additional file 3: Table S1). Most of these 28 QTLs were related to vocalizations (14 out of the 28 significant QTLs, Additional file 3: Table S1); the other QTLs were related to locomotor activity, proximity to flock-mates and the human, the mean distance separating the human and the lamb and vigilance postures. A significant QTL reaching the 5\% CW threshold associated with cortisol concentrations (CORT) was mapped on OAR19. Mean QTL effects ranged from 0.18 to 0.30 phenotypic standard deviations.

Seventy percent of the QTLs mapped to 6 chromosomes (OAR5, 12, 13, 16, 17, 21) and almost all of the significant QTLs reaching either the $1 \% \mathrm{CW}$ threshold or GW thresholds were clustered on 4 of these 6 chromosomes (OAR5, 12, 16, 21). On OAR16, a QTL region mapped between 39.5 and $49.8 \mathrm{Mb}$ was repeatedly associated with high bleat vocalizations (FACTOR1) expressed in sheep subject to social isolation (ISO_HBLEAT, AT1HBLEAT, IBT-HBLEAT) or in the presence of a human (AT2-HBLEAT) (Figure 1). A QTL for the mean distance separating the human and the lamb (CT2-DIST) also mapped on OAR16 in the confidence interval found for high bleat vocalizations. Four QTLs related to high bleat vocalizations (IBT/CT1/ISO-HBLEAT, FACTOR1) were also mapped on OAR5 but in two distinct regions with no overlap of the confidence intervals. A QTL region on OAR21 (10 Mb large) was significantly associated with low bleat vocalization traits (FACTOR4, ISO_LBLEAT, AT1-LBLEAT, CT1-LBLEAT) (Figure 2). Two other QTLs reaching the $5 \% \mathrm{CW}$ threshold and related to high bleat vocalization (AT2-HBLEAT, CT1-HBLEAT) were also mapped to a location $2 \mathrm{Mb}$ from the previous OAR21 region (Additional file 3: Table S1). On OAR12, a QTL region with a narrow confidence interval was associated with low bleat traits (FACTOR4, ISO_LBLEAT, AT1LBLEAT, CT1-LBLEAT) (Figure 3).

\section{Association analysis (GWAS) and joint linkage and association analysis (LDLA)}

The QTLs reaching the 1\% CW significance threshold or the GW significance thresholds (5\%, $1 \%$ or $0.1 \%$ ) found using association analysis (GWAS) are reported in Table 3. QTLs reaching the 5\% CW threshold are also reported in Table 3 if the QTL was also found for the same trait using linkage analysis. Complete lists of QTLs found by GWAS or joint linkage and association analysis (LDLA) are reported in Additional file 4: Table S2 and Additional file 5: Table S3, respectively.

Using GWAS, 16 haplotype-trait associations reached the $1 \% \mathrm{CW}$ significance threshold and 12 haplotype-trait associations reached the GW significance thresholds (Table 3). Nineteen of these 28 QTLs were related to 
Table 2 Summary of QTLs detected in Linkage Analyses studies

\begin{tabular}{|c|c|c|c|c|c|c|}
\hline OAR & Trait & Signifi-cance $^{1}$ & Level & Position $^{2}$ (Mb) & Confidence Interval & Average QTL Effect $^{3}$ \\
\hline 5 & FACTOR1 & $* *$ & $\mathrm{CW}$ & 93.8 & $92.0-95.3$ & 0.26 \\
\hline 5 & ISO_HBLEAT & $* *$ & CW & 96.8 & $92.8-97.3$ & 0.22 \\
\hline 5 & CT1-HBLEAT & $*$ & GW & 93.7 & $92.0-95.4$ & 0.25 \\
\hline 5 & IBT-HBLEAT & * & GW & 52.6 & $47.0-55.0$ & 0.22 \\
\hline 6 & FACTOR2 & $* *$ & CW & 111.7 & $111.6-111.8$ & 0.22 \\
\hline 10 & AT2-LOCOM & $* *$ & CW & 16.1 & $14.2-17.8$ & 0.20 \\
\hline 12 & FACTOR4 & * & CW & 69.0 & $63.7-71.1$ & 0.20 \\
\hline 12 & ISO_LBLEAT & * & GW & 67.8 & $65.6-70.9$ & 0.22 \\
\hline 12 & AT1-LBLEAT & * & CW & 70.4 & $66.4-71.2$ & 0.27 \\
\hline 12 & CT1-LBLEAT & $* *$ & CW & $27.5(68.4)(68.4)$ & $26.1-29.1$ & 0.21 \\
\hline 12 & CT2-DIST & * & CW & 33.1 & $29.7-39.4$ & 0.23 \\
\hline 13 & FACTOR1 & * & $C W$ & 41.4 & $37.1-43.1$ & 0.16 \\
\hline 13 & ISO_HBLEAT & * & CW & 39.7 & $37.5-43.9$ & 0.22 \\
\hline 13 & CT1-HBLEAT & $* *$ & GW & 41.4 & $40.5-44.0$ & 0.27 \\
\hline 16 & FACTOR1 & $* * *$ & GW & 45.2 & $41.9-48.1$ & 0.24 \\
\hline 16 & ISO_HBLEAT & $* *$ & $\mathrm{CW}$ & 43.7 & $41.3-49.8$ & 0.24 \\
\hline 16 & AT1-HBLEAT & * & CW & 47.7 & $39.5-49.8$ & 0.21 \\
\hline 16 & AT2-HBLEAT & $* * *$ & GW & 45.1 & $41.7-46.6$ & 0.30 \\
\hline 16 & IBT-HBLEAT & * & CW & 45.8 & $42.2-48.8$ & 0.25 \\
\hline 16 & CT2-DIST & $* *$ & CW & $34.4(48.0)$ & $33.0-36.8$ & 0.24 \\
\hline 17 & CT1-HBLEAT & $* *$ & $C W$ & 39.0 & $35.1-42.3$ & 0.19 \\
\hline 17 & ISO_LBLEAT & * & GW & 33.3 & $30.5-36.8$ & 0.26 \\
\hline 17 & IBT-LOCOM & * & $\mathrm{CW}$ & 66.4 & $64.7-72.0$ & 0.21 \\
\hline 19 & CORT & * & CW & 41.0 & $38.9-43.2$ & 0.27 \\
\hline 20 & IBT-LOCOM & $* *$ & CW & 38.3 & $36.9-43.2$ & 0.26 \\
\hline 21 & FACTOR4 & $* * *$ & GW & 47.6 & $45.9-48.5$ & 0.27 \\
\hline 21 & AT2-HBLEAT & * & CW & 36.0 & $14.7-37.1$ & 0.19 \\
\hline 21 & ISO_LBLEAT & $* *$ & GW & 39.3 & $38.1-40.0$ & 0.26 \\
\hline 21 & AT1-LBLEAT & $* *$ & CW & 39.3 & $37.9-41.6$ & 0.22 \\
\hline 21 & CT1-LBLEAT & * & GW & 47.3 & $46.5-48.4$ & 0.26 \\
\hline 24 & CT1-LBLEAT & $* *$ & CW & 9.8 & $9.1-11.7$ & 0.19 \\
\hline 26 & FACTOR2 & * & $C W$ & 42.45 & $41.9-44.7$ & 0.21 \\
\hline
\end{tabular}

Only the significant QTLs reaching the $1 \%$ chromosome-wise threshold or the genome-wise thresholds are listed in the table. QTLs reaching the $5 \%$ chromosome-wise threshold are also reported if the QTL was also detected for the same trait by association analysis (GWAS). ${ }^{1}:{ }^{*}, p<5 \%$; **, $p<1 \%$; ***, $p<0.1 \%$. ${ }^{2}$ : the position of a second significant QTL is indicated between parentheses. ${ }^{3}$ : average QTL effect given in phenotypic standard deviation. CW, Chromosome Wide; GW, Genome Wide.

vocalizations (AT2/ISO-HBLEAT, FACTOR1, AT1/AT2/ ISO-LBLEAT, FACTOR4). Seven QTLs were related to the mean distance separating the human and the lamb (CT2-DIST), or to the time during which the human could see the lamb (CT2-SEEN), or to a combination of both traits (HUMAPPRO, FACTOR2). Two QTLs were related to locomotor activity (AT2-LOCOM).

All the significant QTLs that reached the $1 \% \mathrm{CW}$ threshold or GW thresholds found by GWAS were also detected by LDLA analysis (Additional file 5: Table S3).
Among the 28 QTLs detected by GWAS, 9 were also found by linkage analysis. In addition, 72 significant QTLs reaching the 5\% CW threshold were found by association analysis. Most of these QTL were related to vocalizations (43 of the 72 QTLs, Additional file 4: Table S2). All of the QTLs reaching the 5\% CW significance threshold detected by GWAS that were found for the same trait by linkage analysis were also detected by LDLA (with a $1 \%$ genome-wise significance p-value for LDLA). 


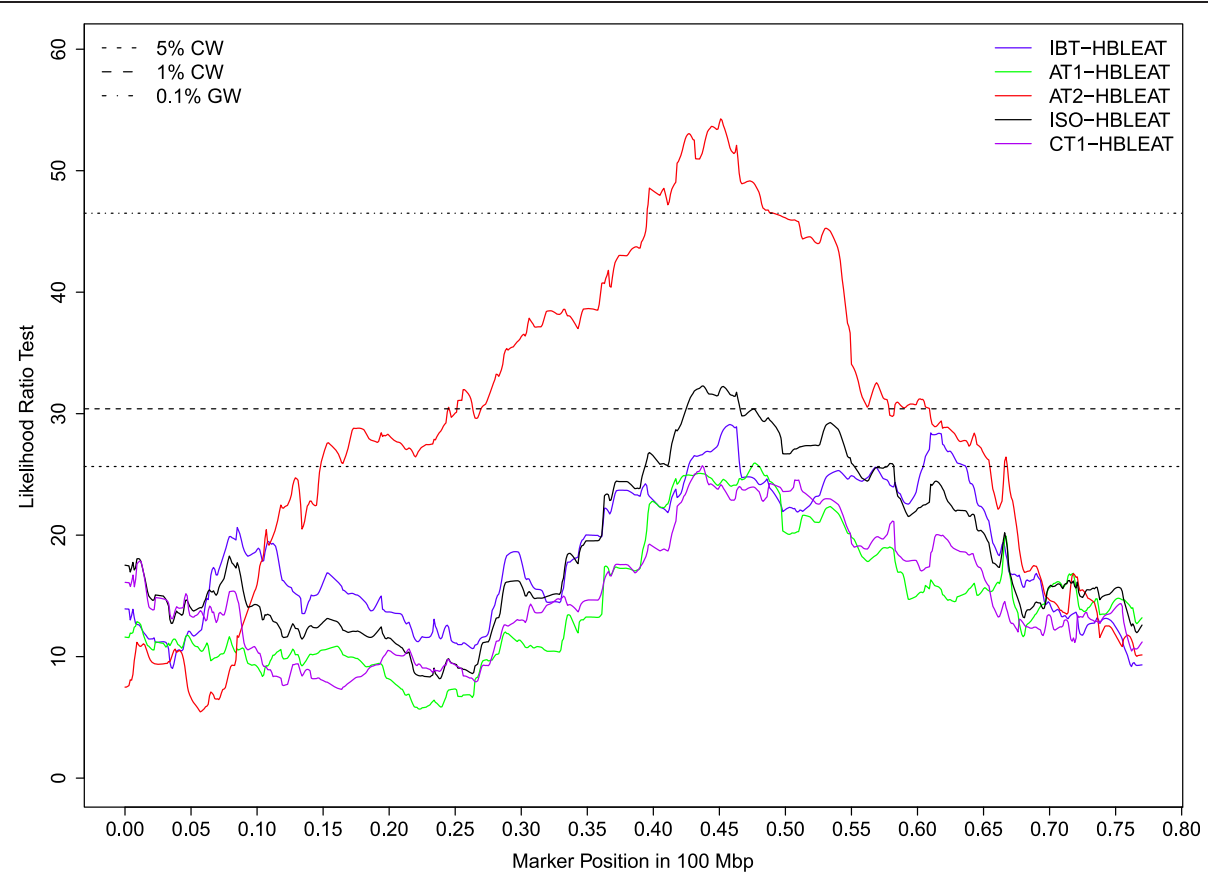

Figure 1 Likelihood profiles of the linkage analyses on OAR16 for high bleat vocalization in the isolation box test (IBT-HBLEAT), arena test phase 1 (AT1-HBLEAT), arena test phase 2 (AT2-HBLEAT), corridor test phase 1 (CT1-HBLEAT) and for the synthetic variable ISO-HBLEAT. Horizontal lines indicate average thresholds for the five HBLEAT traits at the 5\% chromosome wide threshold (5\% CW), 1\% chromosome wide threshold ( $1 \% \mathrm{CW})$ and $0.1 \%$ genome wide threshold $(0.1 \% \mathrm{GW})$.

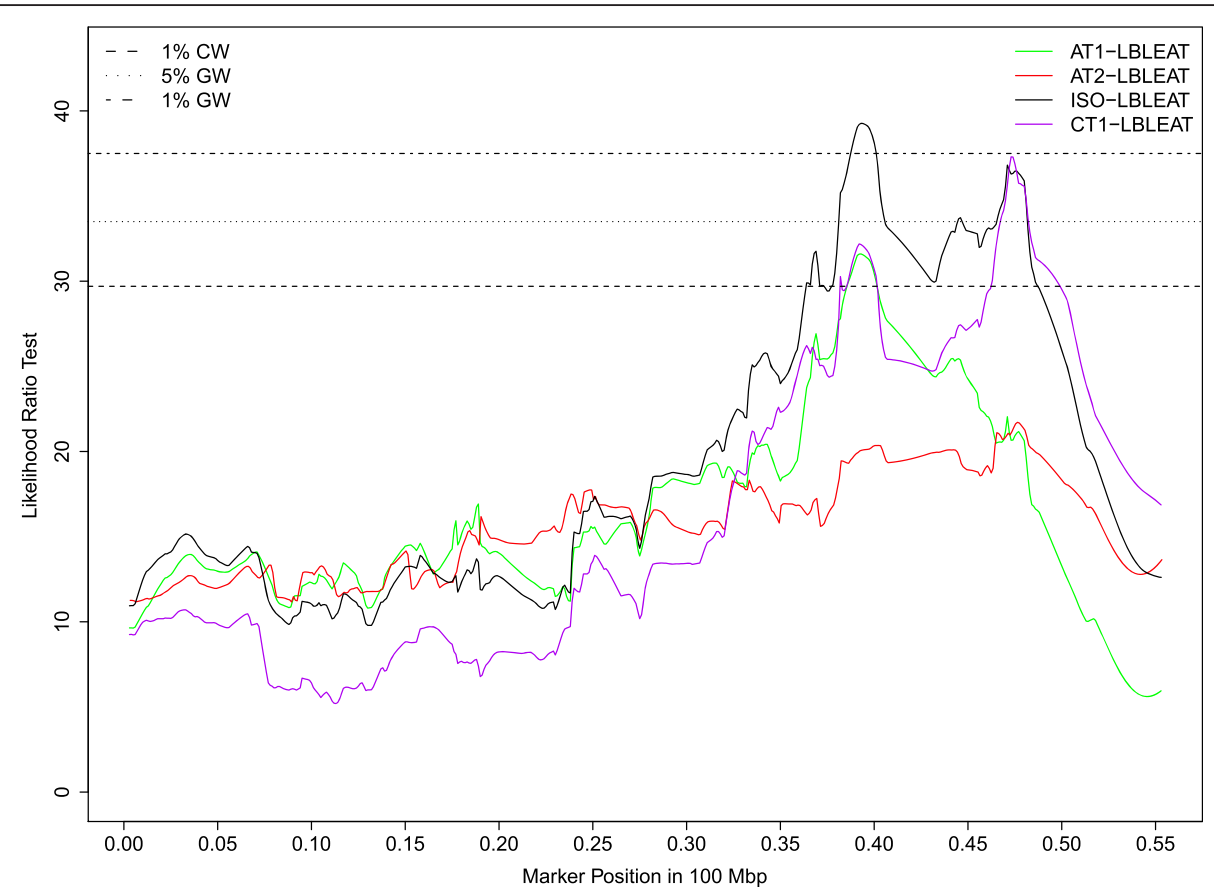

Figure 2 Likelihood profiles of the linkage analyses on OAR21 for low bleat vocalization in the arena test phase 1 (AT1-LBLEAT), arena test phase 2 (AT2-LBLEAT), corridor test phase 1 (CT1-LBLEAT) and for the synthetic variable ISO-LBLEAT. Horizontal lines indicate average thresholds for the four LBLEAT traits at the 1\% chromosome wide threshold (1\% CW), 5\% genome wide threshold (5\% GW) and 1\% genome wide threshold ( $1 \% \mathrm{GW})$. 


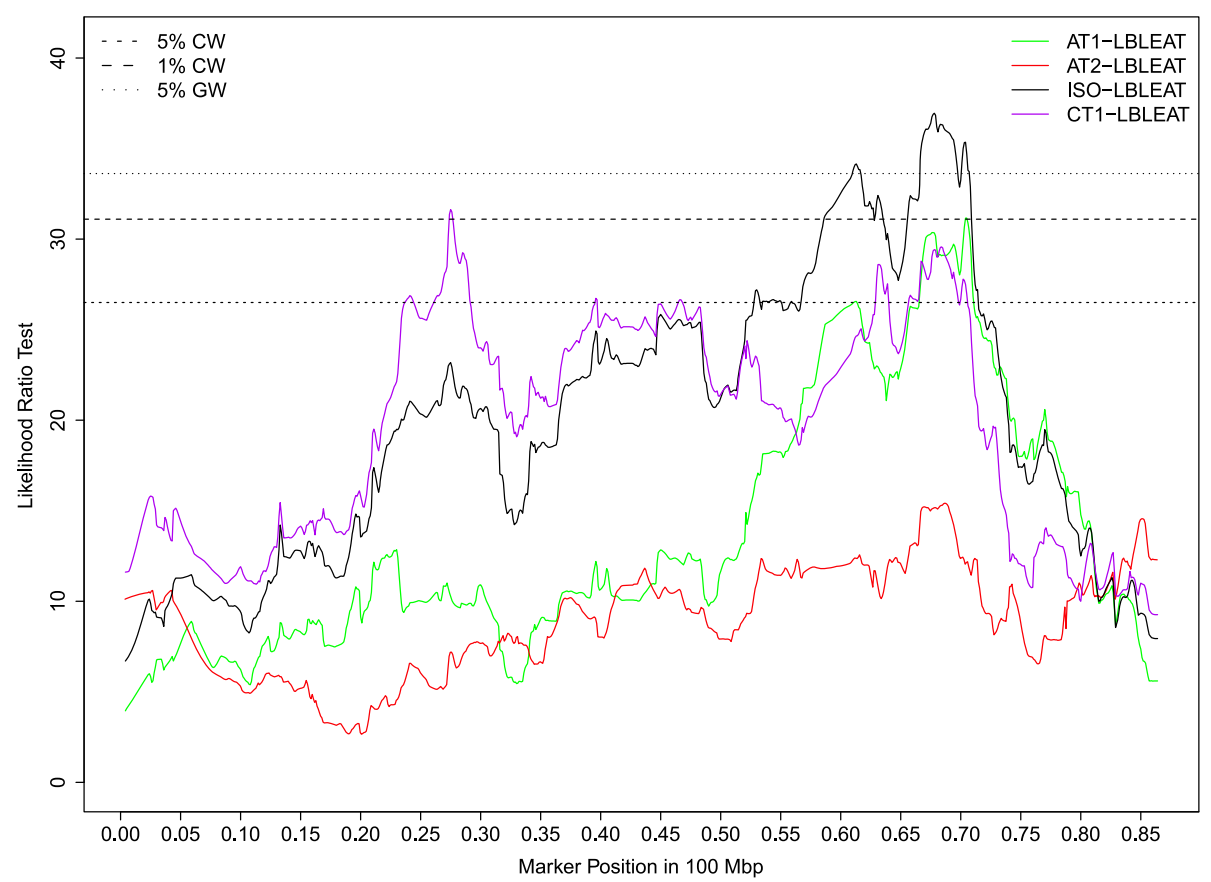

Figure 3 Likelihood profiles of the linkage analyses on OAR12 for low bleat vocalization in the arena test phase 1 (AT1-LBLEAT), arena test phase 2 (AT2-LBLEAT), corridor test phase 1 (CT1-LBLEAT) and for the synthetic variable ISO-LBLEAT. Horizontal lines indicate average thresholds for the four LBLEAT traits at the 5\% chromosome wide threshold (5\% CW), 1\% chromosome wide threshold (1\% CW) and 5\% genome wide threshold ( $5 \% \mathrm{GW})$.

Chromosomes OAR2, 12, 13, 16, 17 and 21 showed consistent associations using the three different analysis methods (i.e. 17 QTLs were detected whatever the analysis method). Three of these six chromosomes were already highlighted by LA (OAR12, 16, 21). Five associations related to high bleats mapped to the same QTL region on OAR16 as found with LA (AT1/AT2/IBT/ISO-HBLEAT, FACTOR1; 42.7 - $46.8 \mathrm{Mb}$ ). The likelihood ratio test profiles for ISO-HBLEAT and AT2-HBLEAT obtained on OAR16 with the linkage and association analyses are shown in Figure 4A and B, respectively. A QTL for the mean distance separating the human and the lamb (CT2-DIST) was also mapped on OAR16 within the confidence interval of the high-bleat region. Four associations related to lowbleating behavior (AT1/AT2/ISO-LBLEAT, FACTOR4) were found on OAR12, close to the confidence interval determined by LA. The likelihood ratio test profiles for ISOLBLEAT obtained with linkage and association analyses on OAR12 are shown in Figure 5. Another QTL for the mean distance separating the human and the lamb (CT2-DIST) was also mapped on OAR12 within the region highlighted by LA for this trait. Three associations for vocalization behaviors (AT2/ISO-HBLEAT, FACTOR1) were found on OAR21 in the same QTL region as found with LA. Last, an association related to corticosterone concentrations was mapped on OAR19 in the same QTL region as found with LA for this trait (Figure 6).
In addition, other chromosomes (OAR5, 7, 8, 15, 19, 20, 23 and 26) exhibited significant associations only found with both association analyses. Among these associations, it can be noted that locomotor activity (AT2-LOCOM, Figure 7) mapped to OAR19 and OAR23, the time during which the human saw the lamb (CT2-SEEN) mapped to OAR20 and OAR23, and the combination of the time during which the human saw the lamb and the mean distance separating the human and the lamb (HUMAPPRO, FACTOR2) mapped to OAR23.

\section{Discussion}

Considering the existing genetic variability for behavioral traits previously reported in sheep [25,35,58], the aim of the present study was to provide the first characterization of the genetic architecture controlling behavioral reactivity to conspecifics and a human in domestic sheep. This was achieved not only by using dense molecular information (Ovine 50kSNP BeadChip) but also by studying a broad range of behavioral phenotypes and using complementary methods of analysis to detect robust and fine-mapped QTLs.

The first QTLs for behavioral responses in domestic sheep As far as we know, we have mapped the first published QTLs for behavioral traits in domestic sheep. Indeed, although the increased awareness to welfare standards in 
Table 3 Summary of QTL detected in GWAS

\begin{tabular}{|c|c|c|c|c|c|c|c|c|}
\hline OAR & Trait & Signifi-cance $^{1}$ & level & $\operatorname{Pos}^{2}(\mathrm{Mb})$ & Confidence interval & No. haplo-types & Flanking & markers $^{3}$ \\
\hline 2 & FACTOR1 & * & GW & 143.8 & $143.7-143.9$ & 11 & s01640.1 & OAR2_143893183.1 \\
\hline 2 & ISO_HBLEAT & $* *$ & CW & 143.8 & $143.7-151.1$ & 11 & s01640.1 & OAR2_143893183.1 \\
\hline 3 & FACTOR4 & $* *$ & CW & 136.8 & $136.7-136.9$ & 9 & OAR3_136802294.1 & OAR3_136865536.1 \\
\hline 5 & FACTOR1 & * & $C W$ & 92.1 & $92.0-92.2$ & 11 & OAR5_92064206.1 & OAR5_92169254.1 \\
\hline 5 & AT1-LBLEAT & $* *$ & $\mathrm{CW}$ & 80.3 & $74.3-80.4$ & 10 & OAR5_80246247.1 & OAR5_80304302.1 \\
\hline 6 & FACTOR2 & $* *$ & CW & 110.0 & $100.1-113.2$ & 9 & s29906.1 & OAR6_110056838.1 \\
\hline 7 & ISO_LBLEAT & $* *$ & CW & 52.1 & $43.5-52.2$ & 9 & OAR7_52124140.1 & OAR7_52157129.1 \\
\hline 8 & AT1-LBLEAT & * & GW & 69.1 & $60.9-69.2$ & 10 & OAR8_69105959.1 & OAR8_69151787.1 \\
\hline 12 & FACTOR4 & $* *$ & GW & 56.3 & $56.2-56.4$ & 13 & s63508.1 & OAR12_56302501_X.1 \\
\hline 12 & AT1-LBLEAT & * & $C W$ & 56.3 & $53.2-80.5$ & 13 & s63508.1 & OAR12_56302501_X.1 \\
\hline 12 & AT2-LBLEAT & * & GW & 56.3 & $56.1-61.6$ & 13 & s63508.1 & OAR12_56302501_X.1 \\
\hline 12 & CT2-DIST & $* *$ & CW & 32.6 & $25.7-32.7$ & 10 & OAR12_32559849.1 & OAR12_32617508.1 \\
\hline 12 & ISO_LBLEAT & $* *$ & GW & 56.2 & $56.1-56.3$ & 13 & s63508.1 & OAR12_56302501_X.1 \\
\hline 13 & FACTOR1 & $* *$ & CW & 45.6 & $39.3-51.2$ & 13 & s73104.1 & s43103.1 \\
\hline 13 & FACTOR4 & ** & CW & 64.3 & $62.5-64.4$ & 9 & s00952.1 & s70439.1 \\
\hline 13 & CT1-LBLEAT & * & CW & 20.5 & $20.4-29.3$ & 12 & s30126.1 & OAR13_20537279.1 \\
\hline 13 & ISO_HBLEAT & $*$ & CW & 45.6 & $34.0-45.7$ & 13 & s73104.1 & s43103.1 \\
\hline 15 & AT1-LBLEAT & $* * *$ & $\mathrm{CW}$ & 74.8 & $74.7-74.9$ & 10 & OAR15_74759937.1 & OAR15_74809345.1 \\
\hline 16 & FACTOR1 & $* * *$ & GW & 43.9 & $43.8-46.3$ & 11 & OAR16_43833978.1 & OAR16_43916302.1 \\
\hline 16 & AT1-HBLEAT & * & CW & 46.3 & $42.7-46.4$ & 13 & OAR16_46290531.1 & OAR16_46325523.1 \\
\hline 16 & AT2-HBLEAT & $* *$ & GW & $44.3(20.1)$ & $44.0-45.7$ & 14 & OAR16_44325630.1 & s23014.1 \\
\hline 16 & CT2-DIST & * & CW & 45.4 & $45.3-46.3$ & 12 & OAR16_45398511.1 & s17055.1 \\
\hline 16 & IBT-HBLEAT & * & $C W$ & 46.3 & $44.4-46.8$ & 13 & OAR16_46290531.1 & OAR16_46325523.1 \\
\hline 16 & ISO_HBLEAT & * & GW & 43.9 & $43.5-46.7$ & 11 & OAR16_43833978.1 & OAR16_43916302.1 \\
\hline 17 & FACTOR2 & $* * *$ & CW & 5.9 & $5.8-7.3$ & 11 & OAR17_5938733.1 & OAR17_5979442.1 \\
\hline 17 & IBT-LOCOM & $*$ & CW & 40.6 & $22.7-40.7$ & 9 & OAR17_40579701.1 & OAR17_40700344.1 \\
\hline 17 & ISO_HBLEAT & * & CW & 12.7 & $12.6-15.0$ & 12 & s42157.1 & OAR17_12809597.1 \\
\hline 19 & AT2-LOCOM & $* * *$ & GW & 18.9 & $18.8-19.0$ & 9 & OAR19_18888791.1 & s24963.1 \\
\hline 19 & CORT & * & CW & 39.1 & $39.0-41.8$ & 7 & OAR19_39084409.1 & OAR19_39123291.1 \\
\hline 20 & CT2-SEEN & $* *$ & CW & 7.6 & $7.5-7.7$ & 10 & OAR20_7626319.1 & OAR20_7794638.1 \\
\hline 21 & FACTOR1 & $* *$ & $\mathrm{CW}$ & 38.0 & $36.6-40.4$ & 9 & OAR21_38037300_X.1 & OAR21_38087037.1 \\
\hline 21 & AT1-LBLEAT & $*$ & GW & 7.6 & $7.2-7.7$ & 14 & s54902.1 & OAR21_7730122.1 \\
\hline 21 & AT2-HBLEAT & * & CW & 38.0 & $25.3-45.1$ & 9 & OAR21_38037300_X.1 & OAR21_38087037.1 \\
\hline 21 & ISO_HBLEAT & * & CW & 43.1 & $36.6-45.1$ & 10 & OAR21_43118557.1 & s61819.1 \\
\hline 23 & FACTOR2 & * & GW & 32.2 & $32.1-32.4$ & 12 & OAR23_32137172.1 & s55273.1 \\
\hline 23 & AT2-LOCOM & * & GW & 54.1 & $51.6-54.2$ & 10 & OAR23_54064411.1 & s31567.1 \\
\hline 23 & CT2-SEEN & $* *$ & CW & 32.3 & $27.9-32.4$ & 10 & s55273.1 & s74857.1 \\
\hline 23 & HUMAPPRO & $* *$ & CW & 32.2 & $28.9-32.3$ & 12 & OAR23_32137172.1 & s55273.1 \\
\hline 26 & FACTOR1 & $* *$ & CW & 6.4 & $4.5-9.5$ & 10 & s58657.1 & DU481531_204.1 \\
\hline 26 & FACTOR2 & * & CW & 41.2 & $39.8-47.6$ & 10 & OAR26_41166096.1 & s07654.1 \\
\hline 26 & ISO_HBLEAT & $* *$ & CW & 45.4 & $45.3-46.8$ & 13 & s31164.1 & s16475.1 \\
\hline
\end{tabular}

Only the significant QTLs reaching the 1\% chromosome-wise threshold or the genome-wise threshold are listed in the table. QTLs reaching the $5 \%$ chromosomewise threshold are also reported if the QTL was also detected for the same trait by linkage analysis. ${ }^{1}:{ }^{*}, p<5 \%$; ${ }^{* *}, p<1 \%$; ${ }^{* * *}, p<0.1 \%$. ${ }^{2}$ : the position of a second significant QTL is indicated between parentheses. ${ }^{3}$ : SNPs flanking the haplotype with significant association. CW, Chromosome Wide; GW, Genome Wide. 

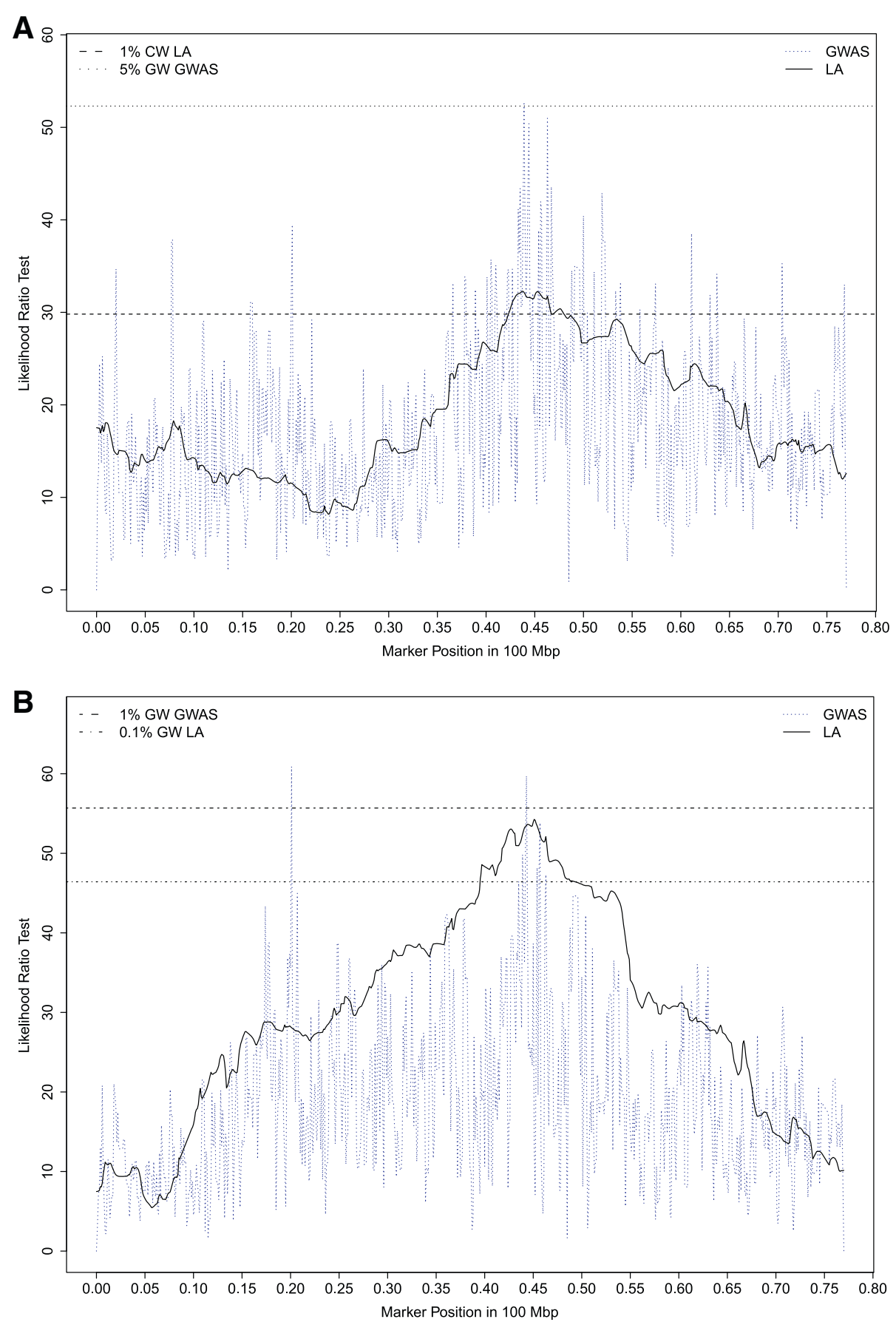

Figure 4 Likelihood ratio test profiles on OAR16 for ISO-HBLEAT with the linkage or association analyses, Likelihood ratio test profiles on OAR16 for AT2-HBLEAT with the linkage or association analyses. A: Horizontal lines indicate the $1 \%$ chromosome wide threshold for linkage analysis (1\% CW LA) and the 5\% genome wide threshold for association analysis (5\% GW GWAS) for ISO-HBLEAT. B: Horizontal lines indicate the $0.1 \%$ genome wide threshold for linkage analysis (0.1\% GW LA) and the 1\% genome wide threshold for association analysis (1\% GW GWAS) for AT2-HBLEAT.

farm animals has led to an growing number of behavioral studies in livestock species [59], especially in sheep, cattle, pigs, poultry and fish [26,60-62], investigations on the genetics of behavior in livestock species are scarce. QTLs for behavior have already been reported in cattle $[40,41]$, pigs [63], poultry [64] and fish [38] but not so far in sheep, albeit for a recent QTL analysis of personality in wild bighorn sheep in which Poissant et al. reported two suggestive QTLs for docility and boldness in response to capture on chromosomes 2 and 6, respectively [65]. However, it is difficult to compare our findings with the behavioral QTLs in bighorn sheep because 


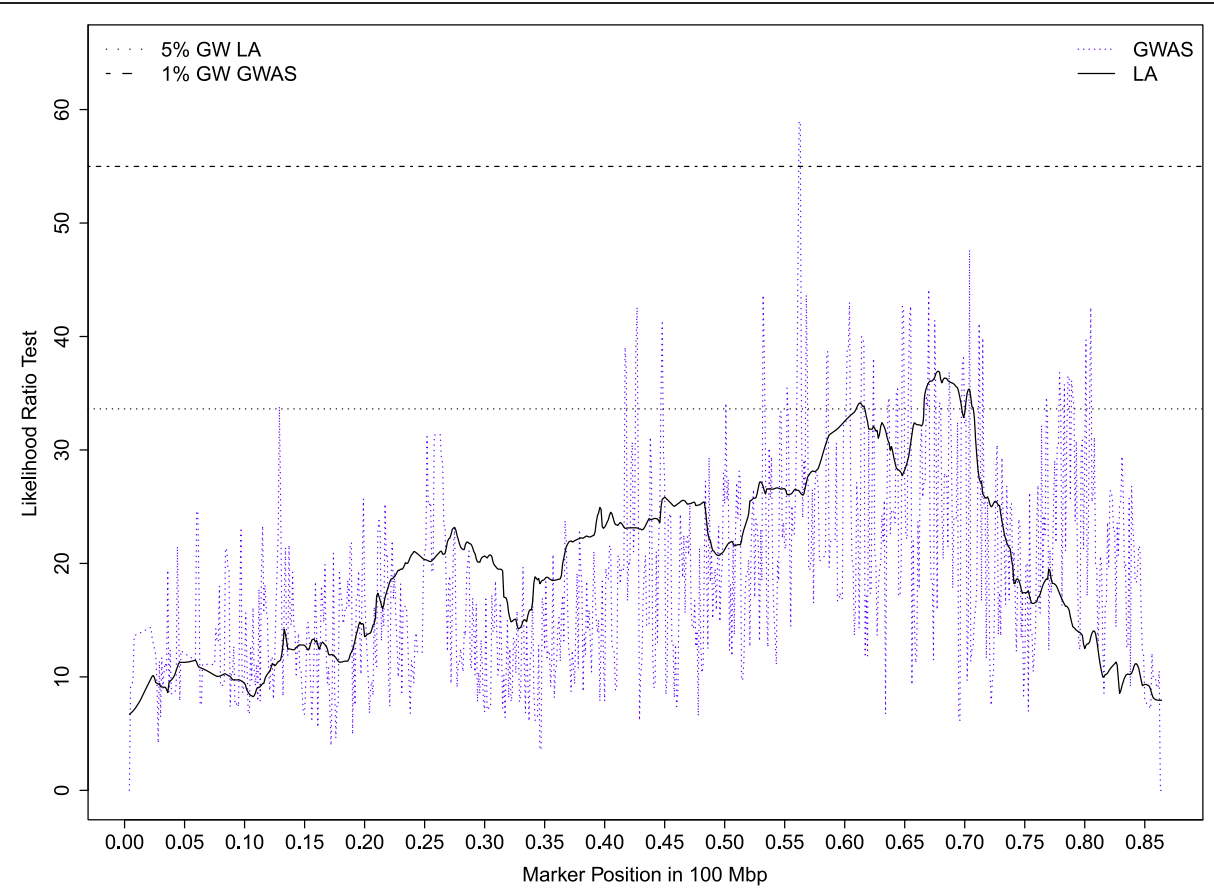

Figure 5 Likelihood ratio test profiles on OAR12 for ISO-LBLEAT with the linkage or association analyses. Horizontal lines indicate the 5\% genome wide threshold for linkage analysis (5\% GW LA) and the 1\% genome wide threshold for association analysis (1\% GW GWAS).

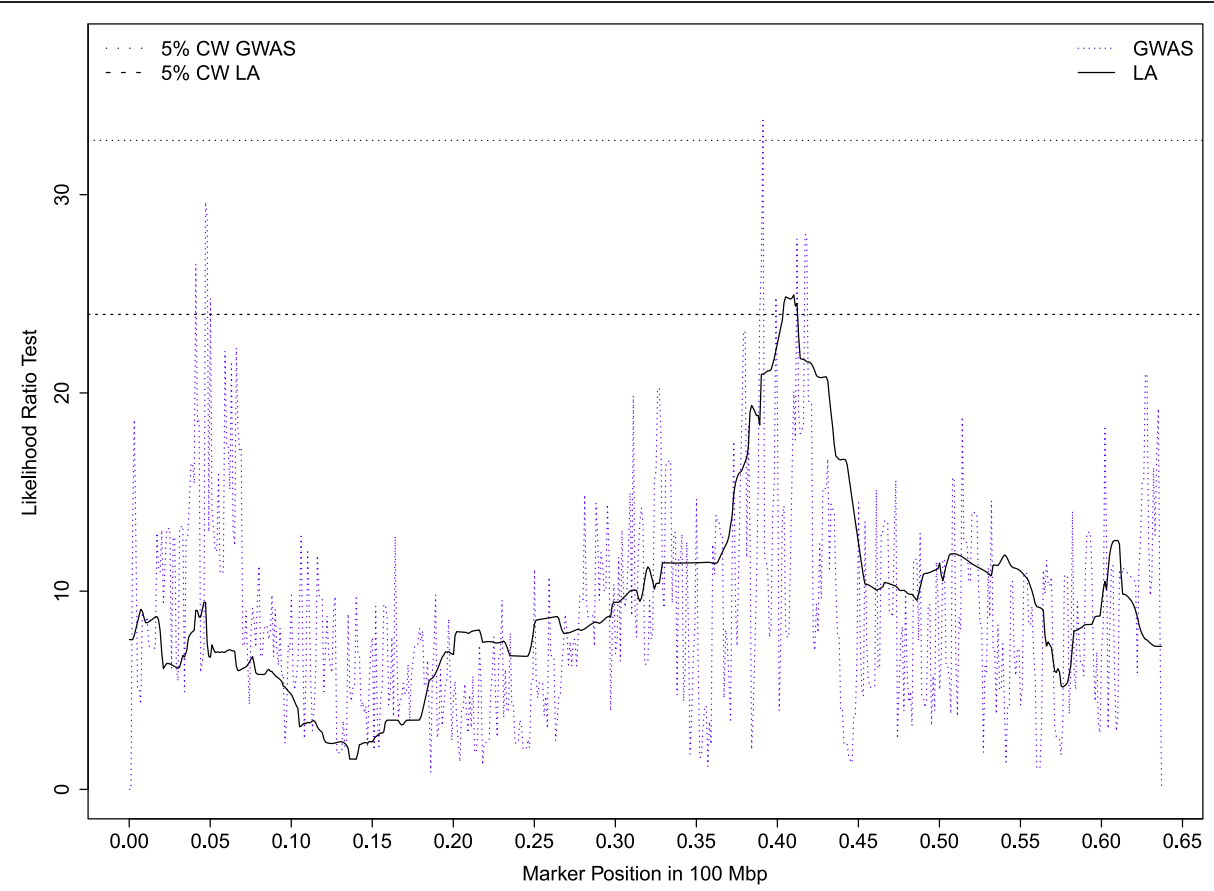

Figure 6 Likelihood ratio test profiles on OAR19 for CORT with the linkage or association analyses. Horizontal lines indicate the 5\% chromosome wide threshold for linkage analysis (5\% CW LA) and the 5\% chromosome wide threshold for association analysis (5\% CW GWAS). 


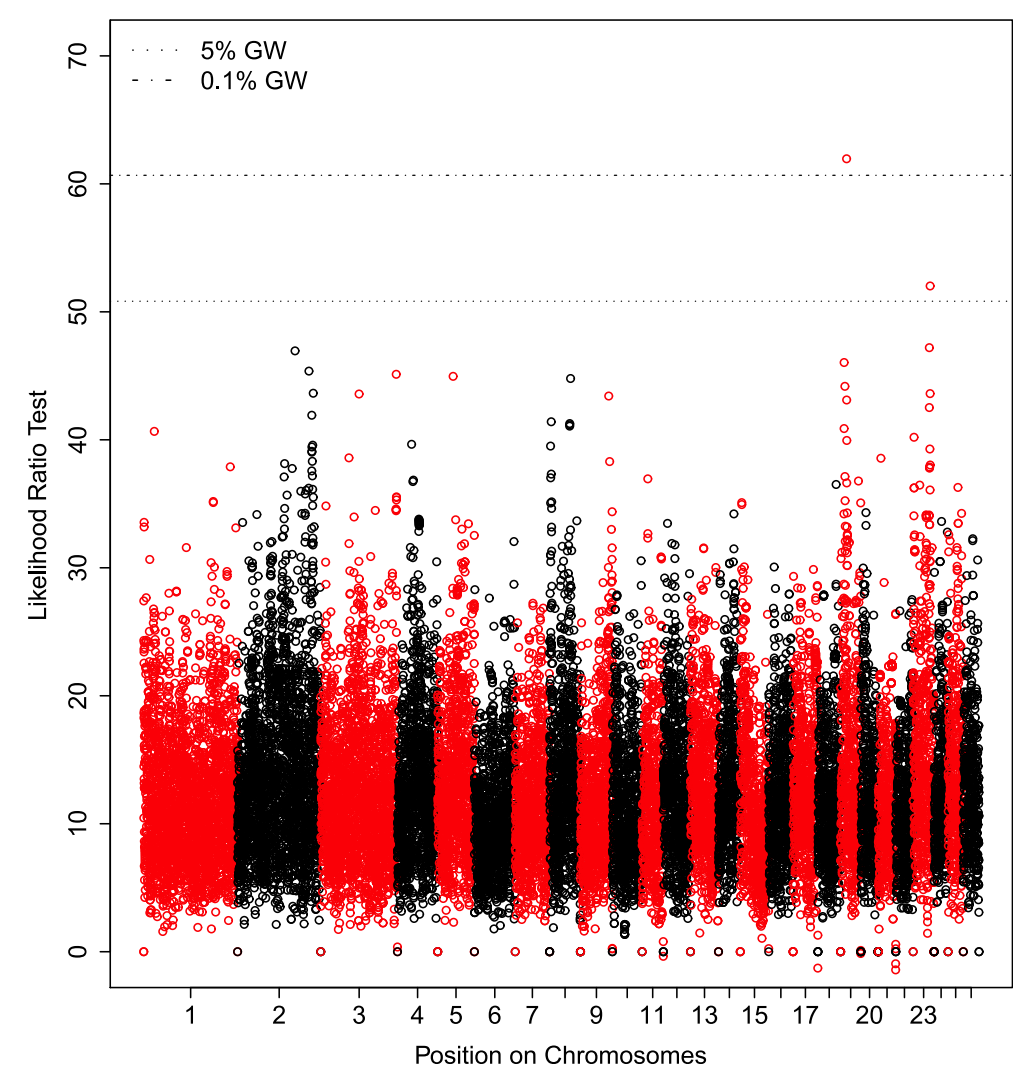

Figure 7 Manhattan plot of the likelihood ratio test values obtained for AT2-LOCOM by GWAS. The likelihood ratio test is plotted against SNP haplotype positions (four consecutive SNPs) along the genome (from chromosome one to 26). Horizontal lines indicate the 5\% genome wide threshold $(5 \% \mathrm{GW})$ or the $0.1 \%$ genome wide threshold $(0.1 \% \mathrm{GW})$ for association analysis.

of the long and divergent evolution history between the Ovis aries (domestic sheep) and Ovis canadensis (bighorn sheep) species in the caprinae subfamily [66].

In our study, we were particularly interested in detecting QTLs for behavioral reactivity and cortisol response in sheep exposed to social isolation, with or without human presence. Both linkage and LD-based analyses resulted in mapping many QTLs involved in reactivity to social and/or human challenges. Findings with the various methods were consistent only for a few regions with several correlated traits mapping to a limited region (OAR12, $16,21,23)$ and/or a high level of significance (OAR5, 8, $12,13,16,19,21)$. The QTL regions detected on OAR12, 16 and 21 were both associated with several correlated traits and showed high levels of significance.

These QTL regions on OAR12, 16 and 21 appeared as the most interesting QTL regions for social reactivity and were mostly associated with low and high bleats, those traits were found the most heritable (Additional file 6: Table S5). Interestingly, QTLs for vocalization have also been reported in cattle [41]. Gutiérrez-Gil et al. found that traits related to the frequency of vocalizations in a social separation test were among the traits with the highest number of QTLs. Other QTLs for behavioral responses to social challenges have been identified in livestock productions (for review see [37]) but were associated with the time spent in a social zone (sociability test), interaction with their mirror image (mirror test) and attack latency (resident intruder test) in chicken [39] or shoaling tendency in zebra fish [38].

Considering original behavioral variables, only the QTLs mapped for similar behavioral traits assessed in the different behavioral tests (i.e. arena, corridor and isolation box tests) were found to overlap. This is particularly the case for the QTL region on OAR16 which is associated with high vocalization measurements, whatever the behavioral test. Similarly, the QTL regions on OAR12 and 21 were both associated with each of the low vocalization measurements, whatever the behavioral test. These results are consistent with the high genetic correlations found between high vocalization measurements and low vocalization measurements. However, the QTLs for high vocalization measurements and low vocalization measurements did not overlap, consistently with the low genetic correlations found between low- and high- bleating behaviors $(-0.3 \pm 0.06)$. Such overlapping of the QTL regions associated with similar traits assessed in the different tests may be due to the stimulus involved in the tests. Indeed, 
the behavioral responses in the different tests could be triggered by the common stimulus that is social isolation in a novel environment, either with or without human proximity.

Consistently with the results obtained for original behavioral variables, no overlaps were detected for the QTLs associated with the 3 specific synthetic variables for reactivity to social isolation (ISO-HBLEAT/LBLEAT/ LOCOM) or with FACTORS (FACTOR1, 3 and 4). Again, this is consistent with the low genetic correlations found between vocalizations and locomotion (0.2 \pm 0.06$)$. All these results suggest that the reactivity to social isolation measured through high and low vocalizations and locomotion is influenced by different loci. This is in line with a previous study in cattle that demonstrated that temperament-related traits measured in a flight-fromfeeder test and a social separation test have different underlying genetic causes [41]. Gutiérrez-Gil et al. reported no overlapping QTLs for flight distance, walkingescaping-running, standing in alert, and vocalizations. The results of anxiety-related behavior studies in mice also suggest that different genetic factors may regulate different aspects of behavior [67]. Using a set of behavioral tests of anxiety including the open-field, elevated plus-maze, square maze, light-dark box and mirror chamber, Turri et al. [67] reported QTLs that influenced behavior in all tests: a first QTL for the general level of motor activity, a second QTL for avoidance behavior and a third QTL for exploratory behavior.

Changes in the social environment can also involve the presence of a human. In our study, we measured reactivity to human presence during a second phase in both arena and corridor tests (traits AT2 and CT2, respectively). Although no QTLs could be detected for locomotion in response to social isolation (phase 1 of arena and corridor tests), we mapped QTLs for locomotion in the presence of a human (AT2-LOCOM) to OAR10, 19, and 23. On OAR19, we determined a haplotype with a large effect (2 phenotypic standard deviations) on locomotion in the presence of a human; however the frequency of this haplotype was low in our study (1\%). In addition, we mapped QTLs for flight distance from a walking human (CT2-DIST), as measured in the corridor test, to chromosomes 12 and 16. The QTL for this trait that was mapped on OAR12 did not overlap with the QTL associated with low bleats. However, on OAR16, the QTL for CT2-DIST overlapped with the QTL associated with high bleats. Nevertheless, the effects of this QTL on OAR16 may not be pleiotropic for both behaviors because the QTL segregated in different set of families depending on the trait. These QTLs found here to be associated with reactivity to humans in sheep were consistent with those detected for similar traits in cattle. Indeed, co-locating QTLs are involved in the determinism of a mobility score and habituation to handling [40], and QTLs that influence the unprovoked flight from a feeder [41] have been found in dairy cattle and/or beef cattle.

We mapped QTLs on OAR16 and OAR21 for high vocalizations and on OAR12 for low vocalizations both recorded in the arena test phase 2. On chromosome 16, the QTL for high vocalizations in the second phase of the arena test overlapped with both of the QTLs for high vocalizations in the first phase of the arena test and the box test. Similarly on chromosome 12, the QTLs for low vocalizations in phases 1 and 2 of the arena test overlapped. These results suggest that the QTLs on chromosomes OAR12, 16 and 21 associated with vocalizations may reflect the reaction to social isolation rather than human presence, whatever the test. In addition, QTLs for the synthetic variable related to the reaction to an approaching human (HUMAPPRO) and for FACTOR2 did not overlap with QTLs for the 3 specific synthetic variables for reactivity to social isolation and for FACTOR1, 3 and 4 . These results suggest that reactivity to humans and reactivity to social isolation are influenced by different loci. This is consistent with the low genetic correlations between vocalization behaviors and reactivity to humans $(0.38 \pm 0.1$ and $-0.36 \pm 0.04$ for high and low vocalizations, respectively) but somewhat contradictory with the high genetic correlations found between locomotion and reactivity to humans $(-0.57 \pm 0.04)$.

\section{Behavioral reactivity in sheep under polygenic influence}

Our results using ovine SNP data support the hypothesis that behavioral traits in domestic sheep are under polygenic influences similarly to other complex traits $[68,69]$ without there being a major effect locus. Nevertheless, several of the QTLs mapped in the present study could probably act together to account for the substantial genetic variation observed for behavioral traits (Additional file 6: Table S5). For the 16 traits considered in the present study, linkage analysis mapped 49 QTLs on 17 chromosomes and only 10 QTLs reached the genomewise significance threshold. Similarly, 100 QTLs were detected on 24 chromosomes with LD-based analysis, with only 12 QTLs reaching the genome-wise significance threshold. The present results from linkage analysis and LD-based analysis are in agreement with other QTL mapping studies for behavioral traits in which relatively few significant QTLs [41] or only suggestive QTLs were detected [65]. Ten years ago, Jonathan Flint [19] reviewed the QTLs that influence behavior in rodents and concluded that a great number of loci had been detected.

The QTL effects detected in the present study explain less than $10.6 \%$ of the phenotypic variation and are consistent with previous QTL studies of behavioral traits in livestock species and rodents. Indeed, Canario et al. [37] recently reviewed the knowledge obtained so far on the 
quantitative genetics of behavioral traits in four livestock species: cattle, pigs, poultry and fish. Whatever the species and behavioral traits, phenotypic variance explained by QTLs was always lower than $10 \%$. For instance, the percentage of the variance explained by the QTLs identified to affect temperament traits in cattle ranged from $3.7 \%$ to $8.41 \%$ [41]. In poultry, several QTLs were found for locomotion, exploration and vocalization as measured by the open field test and for distance covered to join cage-mates in a social motivation test [70-72] but explained only $1.6 \%$ to $4.9 \%$ of the phenotypic variance [70]. In rodents, Flint [19] also showed that most behaviors were influenced by QTLs with small effects, that each contribute to less than $10 \%$ of the phenotypic variance of a behavioral trait.

\section{Genes underlying behavioral reactivity traits}

Despite the preliminary nature of our findings and the need for further studies in order to validate the QTL effects found in our study before being effectively able to conduct a candidate gene approach, it is worth commenting on the genes that may underlie the most relevant QTL effects described here. We used bioinformatics tools $[73,74]$ to search for possible coincidences between our QTL regions (based either on flanking intervals or fine location) and the location of genes that have already been associated with behavioral traits in a variety of mammals. The QTL region on chromosome 16 (39.5-49.8 Mb) associated with both high bleats in response to social separation and flight distance from a human appeared as one of the most interesting regions in which to search for candidate genes. Interestingly, this region coincides with a QTL region found in cattle on chromosome 20 for the flight distance from a feeder [41]. Several coding genes are located close to the fine location of the QTL in this specific region of OAR16 that could be involved in behavioral responses, although no scientific evidence has yet suggested their involvement in regulating behavioral responses. Among these genes, the gene NPR3 (Atrial Natriuretic Peptide Receptor 3, 44.2 Mb) codes for a protein that acts as a clearance receptor for brain natriuretic peptides and helps to regulate blood pressure. Several candidate genes associated with behavioral traits are also located close to or within the QTL region on chromosome 21 (37.9-48.4 Mb) found in our study to be associated with vocalization behaviors (both low and high bleats). This is the case of the gene CHRM1 (cholinergic receptor muscarinic $1,40.6 \mathrm{Mb}$ ). This gene has been described to play a key role in locomotion, cognition and nervous system development [75]. Interestingly, a QTL for a vocalization behavior has been found in cattle on chromosome 29 in a region of conserved synteny [41] but without an identified candidate gene. On chromosome 12, the QTL mapped at 56.3 Mb and associated with low bleats overlaps with the gene ASTN1 (Astrotactin 1, 56.0 Mb). This gene is associated with substance abuse, bipolar disorder and schizophrenia in humans [76]. Finally, the QTL associated with locomotion in response to social isolation on OAR19 (18.9 Mb) maps within the gene GRM7 (Glutamate receptor metabotropic 7, 18.0 Mb) known to be involved in schizophrenia [77]. In addition, this QTL is close to the gene encoding the oxytocin receptor (OXTR, $17.6 \mathrm{Mb}$ ) which is associated with social [78] and maternal behaviors $[79,80]$.

\section{Conclusion}

The work reported here is the first SNP-based QTL detection study for behavioral traits in sheep. We reported various QTLs with low to moderate effects. Five main QTL regions associated with social reactivity and reactivity to humans were identified on OAR12, 16, 19, 21 and 23. These QTL regions contain interesting candidate genes previously described to be associated with various social and/or emotional behaviors in mammals. Ultimately, the identification of genes underlying the behavioral reactivity assessed in our study will provide opportunities for deeper understanding the genetic components involved and will contribute to the general understanding of adaptive traits in animals. If these SNP-trait associations are confirmed, these SNP markers could potentially be used to improve behavioral adaptation in sheep.

\section{Availability of supporting data and requirements}

The data sets supporting the results of this article are included within the article and its additional files. Programs, scripts and other information used to set up the analyses can be obtained from the corresponding author upon request.

\section{Additional files}

\section{Additional file 1: Table S6. Fixed effects and behavioral traits measured in lambs submitted to behavioral tests.}

Additional file 2: Table S4. Factor loadings for the first four extracted factors for each variable from the three behavioral tests included and the variance explained by each factor. This file contains factor loadings for the first four extracted factors for each variable resulting from the factor analysis on the 15 behavioral traits used in this study.

Additional file 3: Table S1. Complete list of QTLs detected by linkage analysis. This file contains a table that lists all the significant QTLs found by linkage analysis for the 16 traits and provides the significance, position of maximum likelihood ratio test, confidence interval and average QTL effect.

Additional file 4: Table S2. Complete list of QTLS detected by GWAS. This file contains a table that lists all the significant QTLs found by association analysis for the 16 traits and provides the significance, position of maximum likelihood ratio test, confidence interval, number of haplotypes and the name of flanking markers.

Additional file 5: Table S3. Complete list of QTLs detected by LDLA analysis. This file contains a table that lists all the significant QTLs found 
by joint linkage and association analysis for the 16 traits and provides the significance, position of maximum likelihood ratio test, confidence interval, number of haplotypes and the name of flanking markers.

Additional file 6: Table S5. Estimates of heritabilities and variances $\pm S$. E for behavioral and physiological traits. This file contains heritability of traits analyzed in this study, proportion of phenotypic variance attributed to maternal, litter and residual effects and the total phenotypic variance for each trait.

\section{Competing interests}

The authors declare that they have no competing interests.

\section{Authors' contributions}

$\mathrm{DH}$ performed the linkage, association and joint linkage and association analyses, interpreted the data and prepared the manuscript. CM contributed to the statistical analyses, results analysis and revised the manuscript. DFo and ED carried out the experiments on animals and performed the behavioral measurements. DFr and JB conceived the genetic experimental design and helped plan the study. DFo was in charge of managing the animals. GS helped to prepare and control the quality of SNP genotypes. $A B$ designed the experiments for behavioral measurements, took part in analyzing and interpreting the results, drafting the manuscript. All authors have read and approved the final manuscript.

\section{Acknowledgements}

The authors would like to thank the INRA Divisions both of Animal Genetics and of Animal Physiology and Livestock Systems for their financial support over the years in providing salaries, experimental costs and computational facilities. The authors are indebted to Paul Autran and all the staff of the experimental farm La Fage for managing the experimental flock as well as for their active role in collecting experimental data. The authors also thank Stéphane Andanson and Christine Ravel of the UMRH for their investment in blood collection and the cortisol assay. Genotyping was funded by ANR and APIS-GENE organizations as part of the project ANR-08-GENM-039 SheepSNPQTL.

\section{Author details}

'INRA, UMR1388 Génétique, Physiologie et Systèmes d'Elevage, F-31326 Castanet-Tolosan, France. ${ }^{2}$ Université de Toulouse INPT ENSAT, UMR1388 Génétique, Physiologie et Systèmes d'Elevage, F-31326 Castanet-Tolosan, France. ${ }^{3}$ Université de Toulouse INPT ENVT, UMR1388 Génétique, Physiologie et Systèmes d'Elevage, F-31076 Toulouse, France. ${ }^{4}$ INRA UE321 La Fage, Saint Jean et Saint Paul, F-12250 Roquefort-sur-Soulzon, France. ${ }^{5}$ INRA UMR1213 Herbivores, F-63122 Saint-Gènes-Champanelle, France. ' $U$ niversité de Clermont, VetAgro Sup, UMR1213 Herbivores, BP 10448, F-63000 Clermont-Fd, France. ${ }^{7}$ Université de Lyon, VetAgro Sup, UMR1213 Herbivores, F-69280 Marcy l'Etoile, France.

Received: 25 April 2014 Accepted: 4 September 2014

Published: 9 September 2014

\section{References}

1. Boissy A, Fisher AD, Bouix J, Hinch GN, Le Neindre P: Genetics of fear in ruminant livestock. Livest Prod Sci 2005, 93(1):23-32.

2. Mason GJ, Cooper J, Clarebrough C: Frustrations of fur-farmed mink. Nature 2001, 410(6824):35-36.

3. Dantzer $\mathrm{R}$, Mormede P: Stress in farm animals - a need for reevaluation. J Anim Sci 1983, 57(1):6-18.

4. Koolhaas JM, de Boer SF, Bohus B: Motivational systems or motivational states: behavioural and physiological evidence. Appl Anim Behav Sci 1997, 53(1):131-143

5. Koolhaas JM, Korte SM, De Boer SF, Van Der Vegt BJ, Van Reenen CG, Hopster H, De Jong IC, Ruis MAW, Blokhuis HJ: Coping styles in animals: current status in behavior and stress-physiology. Neurosci Biobehav Rev 1999, 23(7):925-935.

6. Rauw WM, Kanis E, Noordhuizen-Stassen EN, Grommers FJ: Undesirable side effects of selection for high production efficiency in farm animals: a review. Livest Prod Sci 1998, 56(1):15-33.

7. Rauw WM: Physiological consequences of selection for increased performance. In Proceedings of the Seventeenth Conference of the Association for the Advancement of Animal Breeding and Genetics: 23-26 September 2007; Armidale. Australia: Association for the Advancement of Animal Breeding and Genetics; 2007:240-247.

8. Cockram MS: A review of behavioural and physiological responses of sheep to stressors to identify potential behavioural signs of distress. Anim Welf 2004, 13(3):283-291.

9. Recoquillay J, Leterrier C, Calandreau L, Bertin A, Pitel F, Gourichon D, Vignal A, Beaumont C, Le Bihan-Duval E, Arnould C: Evidence of phenotypic and genetic relationships between sociality, emotional reactivity and production traits in Japanese Quail. Plos One 2013, 8(12):e82157.

10. Porter $\mathrm{RH}$, Nowak $\mathrm{R}$, Orgeur $\mathrm{P}$ : Influence of a conspecific agemate on distress bleating by lambs. Appl Anim Behav Sci 1995, 45(3-4):239-244.

11. Estevez I, Andersen I-L, Nævdal E: Group size, density and social dynamics in farm animals. Appl Anim Behav Sci 2007, 103(3):185-204.

12. Visscher PM, Goddard ME: Genetic Parameters for milk yield, survival, workability, and type traits for australian dairy cattle. J Dairy Sci 1995, 78(1):205-220

13. Burrow HM: Variances and covariances between productive and adaptive traits and temperament in a composite breed of tropical beef cattle. Livest Prod Sci 2001, 70(3):213-233.

14. Kilgour RJ: Arena behaviour is a possible selection criterion for lamb-rearing ability; it can be measured in young rams and ewes. Appl Anim Behav Sci 1998, 57(1):81-89.

15. Hemsworth PH: Human-animal interactions in livestock production. Appl Anim Behav Sci 2003, 81(3):185-198.

16. Rushen J, Taylor AA, de Passillé AM: Domestic animals' fear of humans and its effect on their welfare. Appl Anim Behav Sci 1999, 65(3):285-303.

17. Boissy A, Nowak R, Orgeur P, Veissier I: Social relationships in domestic ruminants: constraints and means for the integration of the animal into its environment. INRA Productions Animales 2001, 14(2):79-90.

18. Mignon-Grasteau S, Boissy A, Bouix J, Faure J-M, Fisher AD, Hinch GN, Jensen $P$, Le Neindre $P$, Mormède $P$, Prunet $P$, Vandeputte $M$, Beaumont $C$ : Genetics of adaptation and domestication in livestock. Livest Prod Sci 2005, 93(1):3-14.

19. Flint J: Analysis of quantitative trait loci that influence animal behavior. J Neurobiol 2003, 54(1):46-77.

20. O'Connell LA, Hofmann HA: Genes, hormones, and circuits: an integrative approach to study the evolution of social behavior. Front Neuroendocrinol 2011, 32(3):320-335.

21. Robinson GE, Fernald RD, Clayton DF: Genes and social behavior. Science 2008, 322(5903):896-900

22. Donaldson ZR, Young $L$ : Oxytocin, vasopressin, and the neurogenetics of sociality. Science 2008, 322(5903):900-904

23. Romeyer A, Bouissou MF: Assessment of fear reactions in domestic sheep and influence of breed and rearing conditions. Appl Anim Behav Sci 1992, 34(1-2):93-119.

24. Vandenheede M, Bouissou MF, Picard M: Interpretation of behavioural reactions of sheep towards fear-eliciting situations. Appl Anim Behav Sci 1998, 58:293-310.

25. Boissy A, Bouix J, Orgeur P, Poindron P, Bibe B, Le Neindre P: Genetic analysis of emotional reactivity in sheep: effects of the genotypes of the lambs and of their dams. Genet Sel Evol 2005, 37(4):381-401.

26. Forkman B, Boissy A, Meunier-Salauen MC, Canali E, Jones RB: A critical review of fear tests used on cattle, pigs, sheep, poultry and horses. Physiol Behav 2007, 92(3):340-374.

27. McBride SD, Wolf B: Using multivariate statistical analysis to measure ovine temperament; stability of factor construction over time and between groups of animals. Appl Anim Behav Sci 2007, 103(1):45-58.

28. Ligout S, Foulquie D, Sebe F, Bouix J, Boissy A: Assessment of sociability in farm animals: the use of arena test in lambs. Appl Anim Behav Sci 2011, 135(1-2):57-62

29. Kilgour RJ, Szantar-Coddington MR: The arena test and cortisol response of sheep as indirect selection criteria for the improvement of lamb survival. Anim Reprod Sci 1997, 46(1):97-108.

30. Beausoleil NJ, Blache D, Stafford KJ, Mellor DJ, Noble ADL: Exploring the basis of divergent selection for 'temperament' in domestic sheep. Appl Anim Behav Sci 2008, 109(2):261-274.

31. Beausoleil NJ, Blache D, Stafford KJ, Mellor DJ, Noble ADL: Selection for temperament in sheep: domain-general and context-specific traits. Appl Anim Behav Sci 2012, 139(1):74-85. 
32. Le Neindre $P$, Poindron $P$, Trillat $G$, Orgeur $P$ : Influence of breed on reactivity of sheep to humans. Genet Sel Evol 1993, 25(5):447-458.

33. Goddard PJ, Fawcett AR, Macdonald AJ, Reid HW: The behavioural, physiological and immunological responses of lambs from two rearing systems and two genotypes to exposure to humans. Appl Anim Behav Sci 2000, 66(4):305-321.

34. Viérin M, Bouissou M-F: Responses of weaned lambs to fear-eliciting situations: origin of individual differences. Dev Psychobio/ 2003, 42(2):131-147

35. Wolf BT, McBride SD, Lewis RM, Davies MH, Haresign W: Estimates of the genetic parameters and repeatability of behavioural traits of sheep in an arena test. Appl Anim Behav Sci 2008, 112(1):68-80.

36. Morris CA, Cullen NG, Kilgour R, Bremner KJ: Some genetic factors affecting temperament in Bos-Taurus cattle. N Z J Agric Res 1994, 37(2):167-175

37. Canario L, Mignon-Grasteau S, Dupont-Nivet M, Phocas F: Genetics of behavioural adaptation of livestock to farming conditions. Animal 2013, 7(3):357-377.

38. Wright D, Nakamichi R, Krause J, Butlin RK: QTL analysis of behavioral and morphological differentiation between wild and laboratory zebrafish (Danio rerio). Behav Genet 2006, 36(2):271-284.

39. Wiren A, Jensen P: A growth QTL on chicken chromosome 1 affects emotionality and sociality. Behav Genet 2011, 41(2):303-311.

40. Schmutz SM, Stookey JM, Winkelman-Sim DC, Waltz CS, Plante Y, Buchanan FC: A QTL study of cattle behavioral traits in embryo transfer families. $J$ Hered 2001, 92(3):290-292.

41. Gutiérrez-Gil B, Ball N, Burton D, Haskell M, Williams JL, Wiener P: Identification of quantitative trait loci affecting cattle temperament J Hered 2008, 99(6):629-638.

42. Mulsant $P$, Lecerf $F$, Fabre $S$, Schibler $L$, Monget $P$, Lanneluc I, Pisselet $C$, Riquet J, Monniaux D, Callebaut I, Cribiu E, Thimonier J, Teyssier J, Bodin L, Cognie Y, Chitour N, Elsen JM: Mutation in bone morphogenetic protein receptor-IB is associated with increased ovulation rate in Booroola Merino ewes. Proc Natl Acad Sci U S A 2001, 98(9):5104-5109.

43. Clop A, Marcq F, Takeda H, Pirottin D, Tordoir X, Bibe B, Bouix J, Caiment F, Elsen JM, Eychenne F, Larzul C, Laville E, Meish F, Milenkovic D, Tobin J, Charlier C, Georges M: A mutation creating a potential illegitimate microRNA target site in the myostatin gene affects muscularity in sheep. Nat Genet 2006, 38(7):813-818.

44. Salle G, Jacquiet $P$, Gruner $L$, Cortet J, Sauve C, Prevot F, Grisez C, Bergeaud JP, Schibler L, Tircazes A, Francois D, Pery C, Bouvier F, Thouly JC, Brunel JC, Legarra A, Elsen JM, Bouix J, Rupp R, Moreno CR: A genome scan for QTL affecting resistance to Haemonchus contortus in sheep. J Anim Sci 2012, 90(13):4690-4705

45. Ibeagha-Awemu EM, Kgwatalala P, Zhao X: A critical analysis of production-associated DNA polymorphisms in the genes of cattle, goat, sheep, and pig. Mamm Genome 2008, 19(9):591-617.

46. Ricordeau G, Tchamitchian L, Brunel J, Nguyen T, François D: La race ovine INRA 401: un exemple de souche synthétique. INRA Productions Animales 1992, 255-262. Hors série.

47. Gonzalez-Garcia E, de Figuereido VG, Foulquie D, Jousserand E, Autran P, Camous S, Tesniere A, Bocquier F, Jouven M: Circannual body reserve dynamics and metabolic profile changes in Romane ewes grazing on rangelands. Domest Anim Endocrinol 2014, 46:37-48.

48. Murphy P, Purvis I, Lindsay D, Le Neindre P, Orgeur P, Poindron P: Measures of temperament are highly repeatable in Merino sheep and some are related to maternal behaviour. Proc Aust Soc Anim Prod 1994, 20:247-254.

49. Boissy A, Bouissou MF: Effects of androgen treatment on behavioural and physiological-responses of heifers to fear-eliciting situations. Horm Behav 1994, 28(1):66-83.

50. Elsen JM, Mangin B, Goffinet B, Boichard D, Le Roy P: Alternative models for QTL detection in livestock -1 general introduction. Genet Sel Evol 1999, 31:213-224.

51. Churchill GA, Doerge RW: Empirical threshold values for quantitative trait mapping. Genetics 1994, 138(3):963-971.

52. Knott SA, Marklund L, Haley CS, Andersson K, Davies W, Ellegren H, Fredholm M, Hansson I, Hoyheim B, Lundström K, Moller M, Andersson L: Multiple marker mapping of quantitative trait loci in a cross between outbred wild boar and large white pigs. Genetics 1998, 149(2):1069-1080

53. Lynch M, Walsh B: Genetics and Analysis of Quantitative Traits. Sunderland, Massachussets: Sinauer Associates; 1998
54. Meuwissen THE, Goddard ME: Fine mapping of quantitative trait loci using linkage disequilibria with closely linked marker loci. Genetics 2000 155:421-430.

55. Legarra A, Fernando RL: Linear models for joint association and linkage QTL mapping. Genet Sel Evol 2009, 41:43.

56. Piepho HP: A quick method for computing approximate thresholds for quantitative trait loci detection. Genetics 2001, 157(1):425-432.

57. Benjamini $Y$, Hochberg $Y$ : Controlling the false discovery rate - A pratical and powerful approach to multiple testing. J R Stat Soc Ser B-Methodol 1995, 57(1):289-300

58. Matheson SM, Bünger L, Dwyer CM: Genetic parameters for fitness and neonatal behavior traits in sheep. Behav Genet 2012, 42(6):899-911.

59. von Borell E, Veissier I: Special section - stress and welfare in farm animals. Physiol Behav 2007, 92(3):291-292.

60. Boissy A, Manteuffel G, Jensen MB, Moe RO, Spruijt B, Keeling LJ, Winckler C, Forkman B, Dimitrov I, Langbein J, Bakken M, Veissier I, Aubert A: Assessment of positive emotions in animals to improve their welfare. Physiol Behav 2007, 92(3):375-397.

61. Veissier I, Boissy A: Stress and welfare: two complementary concepts that are intrinsically related to the animal's point of view. Physiol Behav 2007, 92(3):429-433.

62. Prunet $P$, Overli O, Douxfils J, Bernardini G, Kestemont P, Baron D: Fish welfare and genomics. Fish Physiol Biochem 2012, 38(1):43-60.

63. Désautés C, Bidanel JP, Milan D, lannuccelli N, Amigues Y, Bourgeois F, Caritez JC, Renard C, Chevalet C, Mormède P: Genetic linkage mapping of quantitative trait loci for behavioral and neuroendocrine stress response traits in pigs. J Anim Sci 2002, 80(9):2276-2285.

64. Biscarini F, Bovenhuis $H$, van der Poel J, Rodenburg TB, Jungerius AP, van Arendonk JAM: Across-line SNP association study for direct and associative effects on feather damage in laying hens. Behav Genet 2010, 40(5):715-727

65. Poissant J, Reale D, Martin JGA, Festa-Bianchet M, Coltman DW A quantitative trait locus analysis of personality in wild bighorn sheep. Ecology and Evolution 2013, 3(3):474-481.

66. Hernandez Fernandez M, Vrba ES: A complete estimate of the phylogenetic relationships in Ruminantia: a dated species-level supertree of the extant ruminants. Biol Rev Camb Philos Soc 2005, 80(2):269-302.

67. Turri MG, Datta SR, DeFries J, Henderson ND, Flint J: QTL analysis identifies multiple behavioral dimensions in ethological tests of anxiety in laboratory mice. Current biology : CB 2001, 11(10):725-734.

68. Hayes B, Goddard M: The distribution of the effects of genes affecting quantitative traits in livestock. Genet Sel Evol 2001, 33(3):209-229.

69. Yang J, Manolio TA, Pasquale LR, Boerwinkle E, Caporaso N, Cunningham JM, de Andrade M, Feenstra B, Feingold E, Hayes MG, Hill WG, Landi MT, Alonso A, Lettre G, Lin P, Ling H, Lowe W, Mathias RA, Melbye M, Pugh E, Cornelis MC, Weir BS, Goddard ME, Visscher PM: Genome partitioning of genetic variation for complex traits using common SNPs. Nat Genet 2011, 43(6):519-525

70. Schütz K, Kerje S, Jacobsson L, Forkman B, Carlborg Ö, Andersson L, Jensen $P$ : Major growth QTLs in fowl are related to fearful behavior: possible genetic links between fear responses and production traits in a Red Junglefowl $\times$ White Leghorn intercross. Behav Genet 2004, 34(1):121-130.

71. Buitenhuis AJ, Rodenburg TB, Siwek M, Cornelissen SJB, Nieuwland MGB, Crooijmans R, Groenen MAM, Koene P, Bovenhuis H, van der Poel J: Identification of QTLs involved in open-field behavior in young and adult laying hens. Behav Genet 2004, 34(3):325-333.

72. Buitenhuis AJ, Rodenburg TB, Siwek M, Cornelissen SJB, Nieuwland MGB, Crooijmans R, Groenen MAM, Koene P, Bovenhuis H, van der Poel J J Quantitative trait loci for behavioural traits in chickens. Livest Prod Sci 2005, 93(1):95-103.

73. Narcisse: a mirror view of conserved syntenies. http://narcisse.toulouse inra.fr/animals/cgi-bin/narcisse.cgi.

74. Livestock Genomics. http://www.livestockgenomics.csiro.au/sheep/oar3.1.php.

75. Tanda G, Ebbs AL, Kopajtic TA, Elias LM, Campbell BL, Newman AH, Katz JL: Effects of muscarinic $M-1$ receptor blockade on cocaine-induced elevations of brain dopamine levels and locomotor behavior in rats. J Pharmacol Exp Ther 2007, 321(1):334-344.

76. Hill SY, Weeks DE, Jones BL, Zezza N, Stiffler S: ASTN1 and alcohol dependence: Family-based association analysis in multiplex alcohol dependence families. Am J Med Genet Part B-Neuropsychiatr Genet 2012, 159B(4):445-455. 
77. Shibata H, Tani A, Chikuhara T, Kikuta R, Sakai M, Ninomiya H, Tashiro N, Iwata N, Ozaki N, Fukumaki Y: Association study of polymorphisms in the group III metabotropic glutamate receptor genes, GRM4 and GRM7, with schizophrenia. Psychiatry Res 2009, 167(1-2):88-96.

78. Sala M, Braida D, Donzelli A, Martucci R, Busnelli M, Bulgheroni E, Rubino T, Parolaro D, Nishimori K, Chini B: Mice heterozygous for the oxytocin receptor gene $(\operatorname{Oxtr}(+/-))$ show impaired social behaviour but not increased aggression or cognitive inflexibility: evidence of a selective haploinsufficiency gene effect. J Neuroendocrinol 2013, 25(2):107-118.

79. Champagne F, Diorio J, Sharma S, Meaney MJ: Naturally occurring variations in maternal behavior in the rat are associated with differences in estrogen-inducible central oxytocin receptors. Proc Natl Acad Sci U S A 2001, 98(22):12736-12741.

80. Feldman R, Zagoory-Sharon O, Weisman O, Schneiderman I, Gordon I, Maoz R, Shalev I, Ebstein RP: Sensitive parenting is associated with plasma oxytocin and polymorphisms in the OXTR and CD38 Genes. Biol Psychiatry 2012, 72(3):175-181.

doi:10.1186/1471-2164-15-778

Cite this article as: Hazard et al:: Identification of QTLs for behavioral reactivity to social separation and humans in sheep using the OvineSNP50 BeadChip. BMC Genomics 2014 15:778.

\section{Submit your next manuscript to BioMed Central and take full advantage of:}

- Convenient online submission

- Thorough peer review

- No space constraints or color figure charges

- Immediate publication on acceptance

- Inclusion in PubMed, CAS, Scopus and Google Scholar

- Research which is freely available for redistribution 